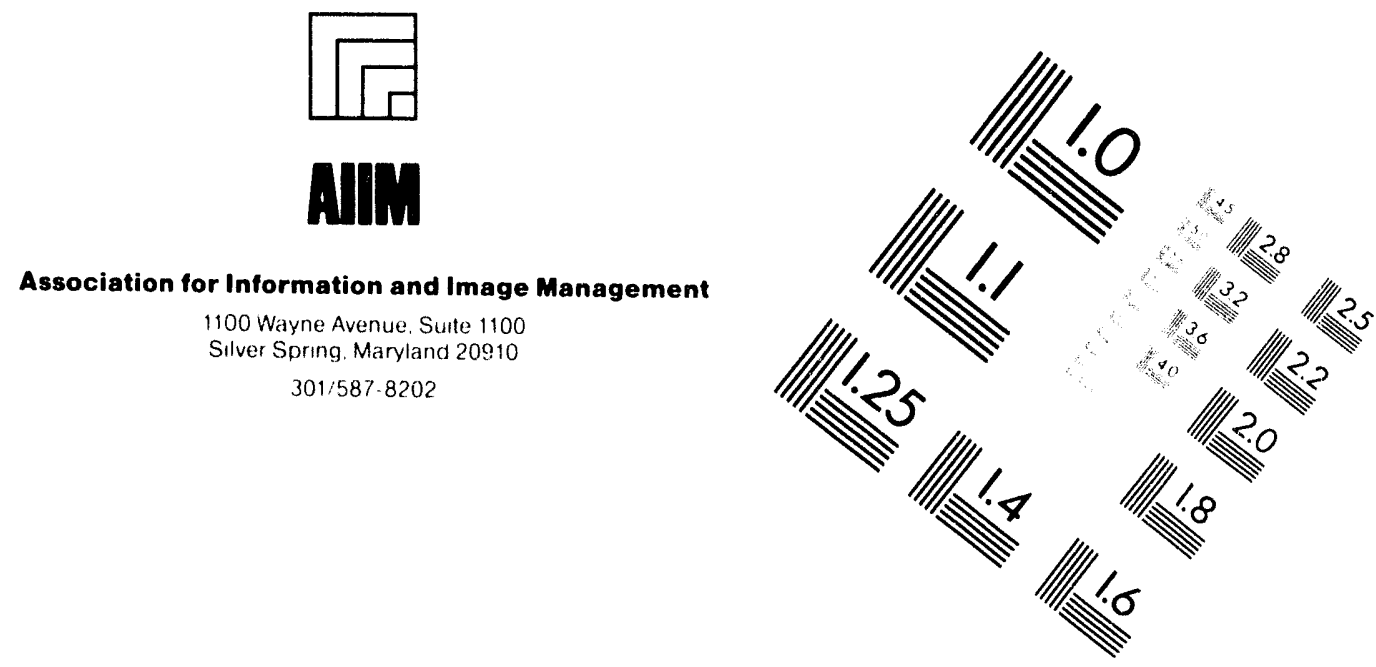

\title{
Centimeter
}

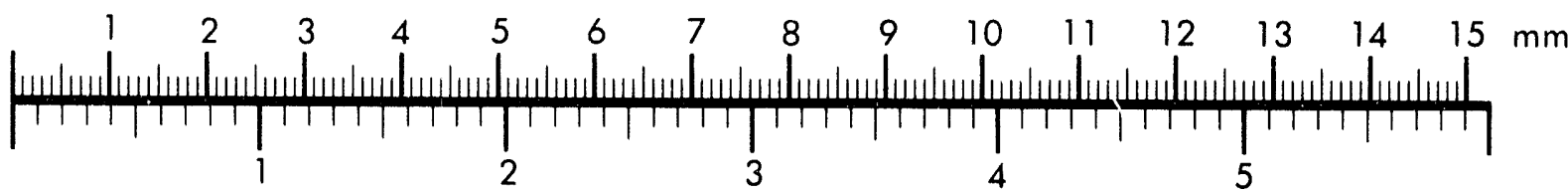
Inches
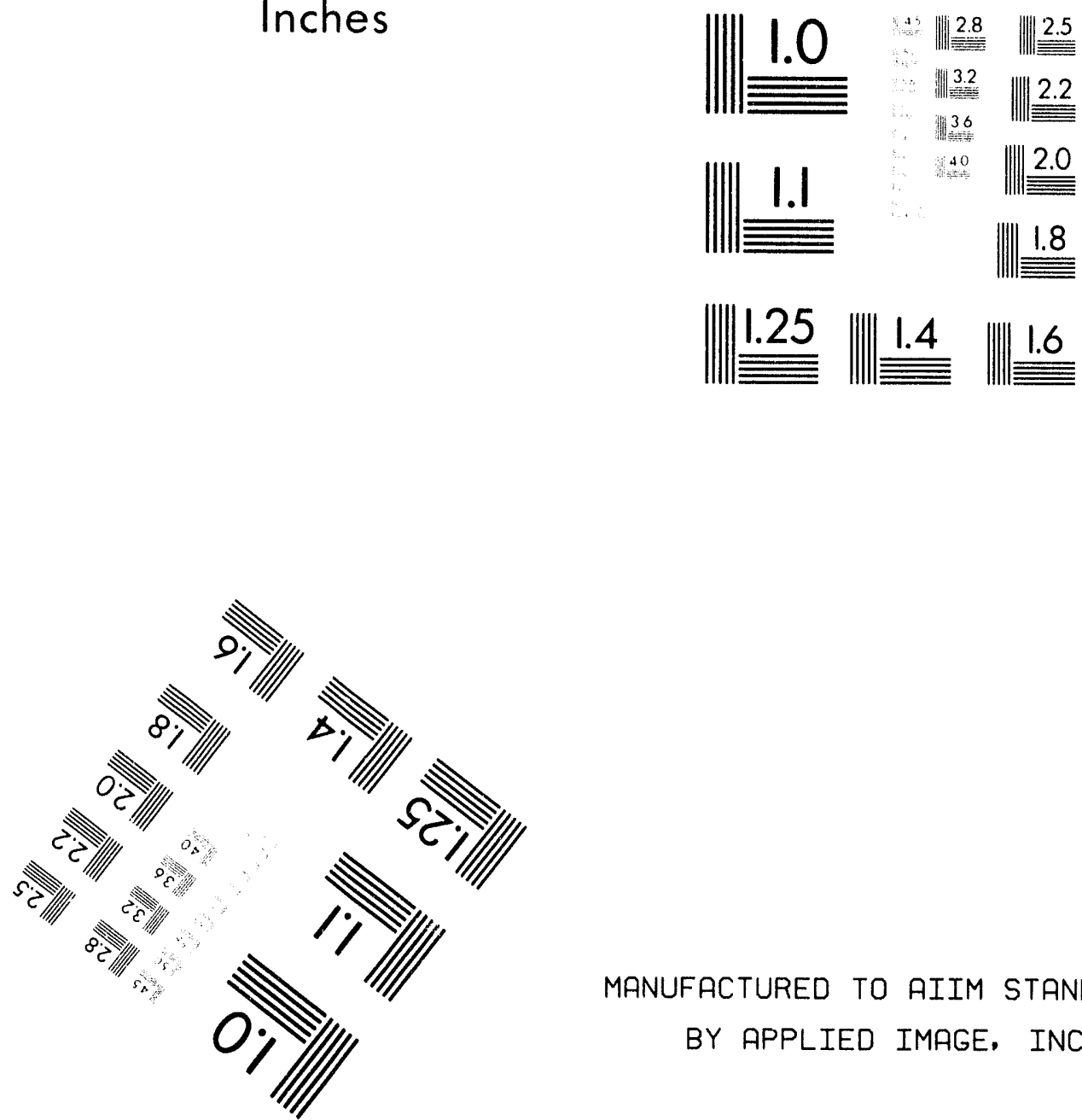

MANUFACTURED TO AIIM STANDARDS BY APPLIED IMAGE, INC.

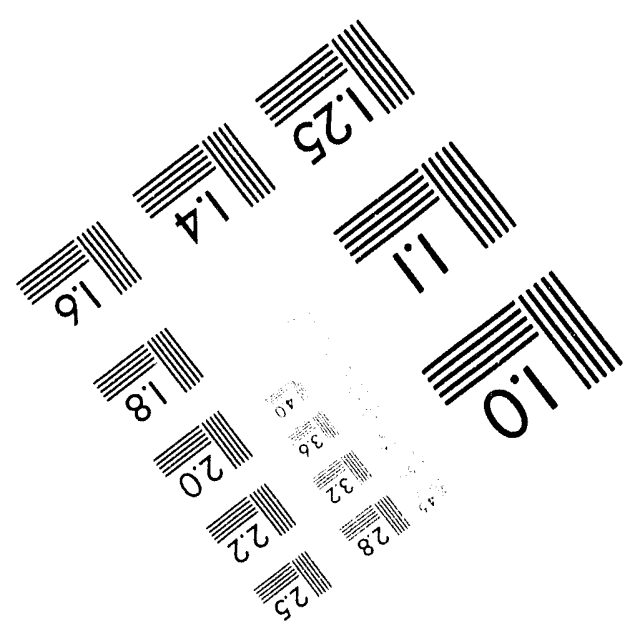



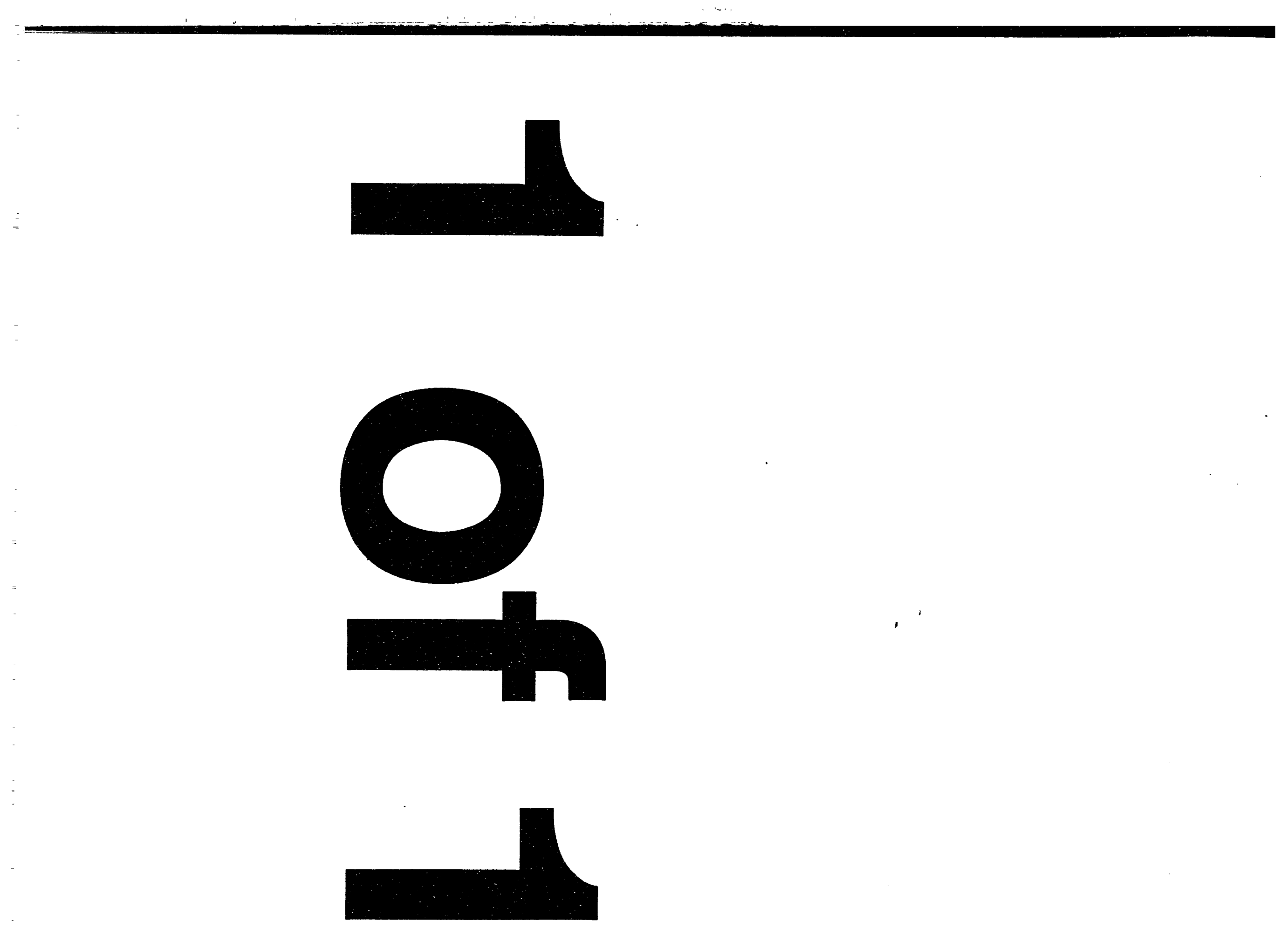
ORNL/CON-352

\section{FINANCIAL COMPARISON OF TIME-OF-USE PRICING WITH TECHNICAL DSM PROGRAMS \\ AND GENERATING PLANTS AS ELECTRIC-UTILITY RESOURCE OPTIONS}

Lawrence J. Hill

Energy Division

Date Published: April 1994

Prepared for

Office of Energy Efficiency and Renewable Energy

U.S. DEPARTMENT OF ENERGY

OAK RIDGE NATIONAL LABORATORY

Oak Ridge, Tennessee 37831

Managed by

MARTIN MARIETTA ENERGY SYSTEMS, INC.

for the

U.S. DEPARTMENT OF ENERGY

under Contract No. DE-AC05-84OR21400 


\section{CONTENTS}

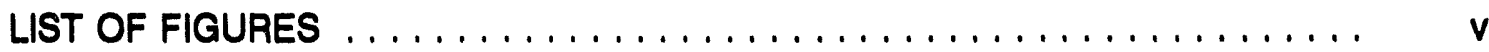

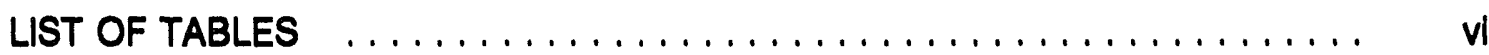

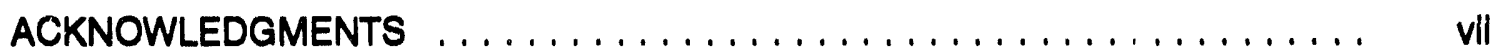

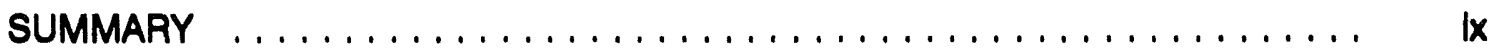

1. INTRODUCTION $\ldots \ldots \ldots \ldots \ldots \ldots \ldots \ldots \ldots \ldots \ldots \ldots \ldots \ldots \ldots$

1.1. Purpose and Scope of the Study $\ldots \ldots \ldots \ldots \ldots \ldots \ldots \ldots \ldots \ldots \ldots, 1.1$

1.2. Approach Used in the Study $\ldots \ldots \ldots \ldots \ldots \ldots \ldots \ldots \ldots \ldots \ldots \ldots \ldots . \ldots \ldots$

1.3. Remainder of the Report $\ldots \ldots \ldots \ldots \ldots \ldots \ldots \ldots \ldots \ldots \ldots \ldots$

2. THE HYPOTHETICAL UTILITY $\ldots \ldots \ldots \ldots \ldots \ldots \ldots \ldots \ldots \ldots \ldots \ldots \ldots$

2.1. Generating Mix and its Characteristics ............... 2.1

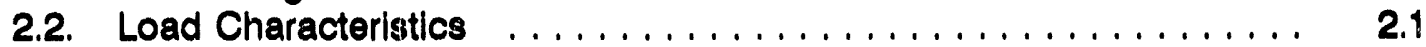

3. TOU PRICING AS A CANDIDATE RESOURCE $\ldots \ldots \ldots \ldots \ldots \ldots \ldots \ldots \ldots$

3.1. Conceptual Underpinnings $\ldots \ldots \ldots \ldots \ldots \ldots \ldots \ldots \ldots \ldots \ldots \ldots \ldots$

3.2. Evidence of TOU Pricing's Effectiveness In Shaping Load . . . . . . . 3.2

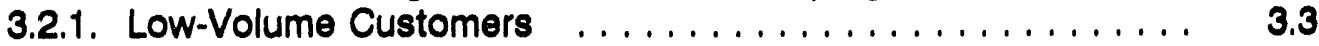

3.2.2. Medium- and High-Volume Customers . . . . . . . . . . 3.5

3.3. Benefits and Costs of TOU Pricing in this Study . . . . . . . . . . . 3.6

4. OTHER CANDIDATE RESOURCES $\ldots \ldots \ldots \ldots \ldots \ldots \ldots \ldots \ldots \ldots$

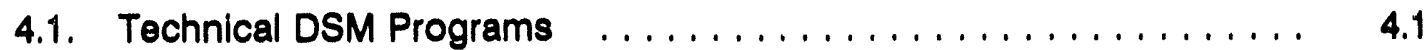

4.2. Generating Plants $\ldots \ldots \ldots \ldots \ldots \ldots \ldots \ldots \ldots \ldots \ldots \ldots$

5. COST-EFFECTIVENESS OF RESOURCE OPTIONS $\ldots \ldots \ldots \ldots \ldots \ldots \ldots$

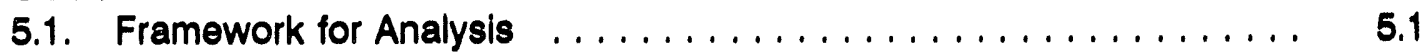

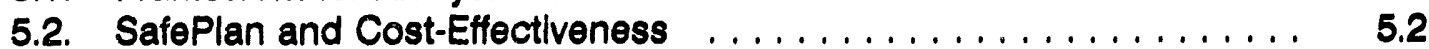

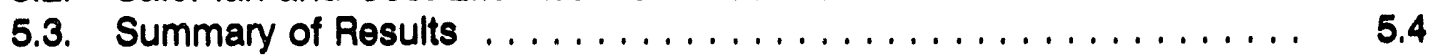

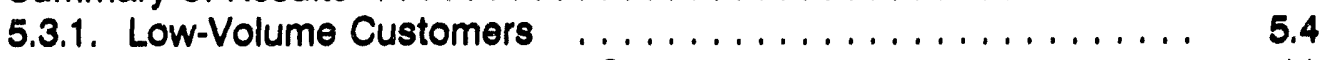

5.3.2. Medium- and High-Volume Customers $\ldots \ldots \ldots \ldots \ldots \ldots .11$

5.3.3. A Closer Look at Pricing . . . . . . . . . . . . . . . 5.13

6. SYNTHESIS AND RECOMMENDATIONS $\ldots \ldots \ldots \ldots \ldots \ldots \ldots \ldots \ldots$

6.1. The Study in Context . . . . . . . . . . . . . . . . . . . 6.1

6.2. Relevance of the Results for Electric-Utility Planning . . . . . . . . 6.1

6.3. A Closer Look at Questions Raised in the Study . . . . . . . . . . . 6.3

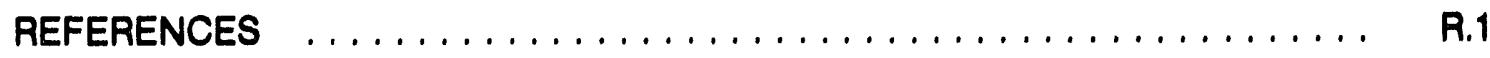




\section{UST OF FIGURES}

Figure

Description

Page

2.1 Three Load Duration Curves for Sensitivity Analysis $\ldots \ldots \ldots \ldots$. . . 2.3

3.1 Load-Curve Effects of TOU Pricing $\ldots \ldots \ldots \ldots \ldots \ldots \ldots$

4.1 Ramp Rates for Technical DSM Programs $\ldots \ldots \ldots \ldots \ldots \ldots . . . . .4$

4.2 Load-Curve Effects, Conservation and Load Management

Programs ....................... 4.4

$5.1 \quad$ Calculation of Benefit-Cost Ratios in SafePlan $\ldots \ldots \ldots \ldots . \ldots$

5.2 Cost-Effectiveness of the TOU Pricing Program, Various

Metering Costs, Low-Volume Customers . . . . . . . . . . . 5.6

5.3 Cost-Effectiveness of the Conservation Program, Various

Conservation Load Factors, Low-Volume Customers . . . . . . . . 5.8

5.4 Benefit-Cost Ratios for TOU Pricing, Varying Peak-Period

Lengths, Three Customer Classes . . . . . . . . . . . . 5.16 


\section{UST OF TABLES}

Table

Description

Page

$2.1 \quad$ Existing Generating Plants and Capacities $\ldots \ldots \ldots \ldots \ldots \ldots$

Assumed Growth in Fuel Prices, $1993-2012 \ldots \ldots \ldots \ldots$. . . . . . . .

3.1 Responses to U.S. Residential TOD Rates, Summer Months,

Different Appliance and Weather Scenarios

3.2 Change in Relative Loads, Introduction of TOU Rates,

U.S. Medium- and High-Volume Customers

3.3

Assumed Responses to TOU Pricing, Load Shape

Changes and Own-Price Elasticities, Three Customer

Classes

Metering Costs, Three Customer Classes

5.1 Benefit-Cost Ratios for Candidate Resources, Low-Volume Customers

5.2 Benefit-Cost Ratios for Candidate Resources, Sensitivities to Input Assumptions, Low-Volume Customers

5.3 Revenue Requirements for Candidate Resources, Low-

Volume Customers

5.4 Benefit-Cost Ratios for Candidate Resources, MediumVolume Customers

5.5 Benefit-Cost Ratios for Candidate Resources, High-

Volume Customers

5.6 Benefit-Cost Ratios for TOU Pricing, Low- vs. Medium- vs.

High-Volume Customers, Benefit-Cost Ratios 


\section{ACKNOWLEDGMENTS}

Although I am listed as the sole author, several other people contributed to this study. I would especially like to thank Eric Hirst of Oak Ridge National Laboratory who provided constructive comments on two earlier draft versions. I would also like to thank Joe Eto of Lawrence Berkeley Laboratory, Ben Hobbs of Case Western Reserve University, Bruce Humphrey of the Edison Electric Institute, Jon Lowell of New England Electric Service, Barry Moline of the American Public Power Association, Ken Rose of the National Regulatory Research. Institute, and Perry Sioshansi of the Electric Power Research Institute. Each provicied comments and raised questions that improved the study's quality. As always, however, I take full responsibility for any errors, mistakes in judgment, or oversights. Finally, I thank Glenda Hamiin, Ed Lapsa, and Ethel Schorn for their technical support. 


\section{SUMMARY}

Changing electricity prices to more closely reflect production costs has a significant impact on the consumption of electricity. It is known, for example, that most of the efficiency gains in the electric power sectors of the industrialized world since the first international oil price shock in 1973 are attributable to the rising trend of electricity prices. This was due to the rising average price of electricity. Because of the unique characteristics of producing electricity, its marginal cost is higher than its average cost during many hours of the day. This study shows that, for utilities not reflecting these cost differences in their rates, there is ample room to satisfy a portion of their resource needs by exploiting the load-shaping properties of time-of-use (TOU) rates.

Satistying a portion of resource requirements by implementing a TOU-pricing program, however, is not costless. Metering and administering TOU pricing requires a financial commitment by an electric utility. And the commitment has an opportunity cost. That is, the funds could be used to construct generating plants or run DSM programs (other than a TOU-pricing program) and satisfy the same resource needs that TOU pricing does.

The question addressed in this study is whether a utility is better-served financially by (i) implementing TOU pricing or (ii) running technical DSM programs and building power plants." The answer is that TOU pricing compares favorably on a financial basis with other resources under a wide set of conditions that real-world utilities confront.

To arrive at this conclusion, we simulate the resource selection process of a hypothetical, "average" electric utility over a 20-year planning horizon using the principles of integrated resource planning (IRP). The utility initially has a system load factor of 0.60 ... the U.S. average--under three different assumptions about load shape (i.e., one-, thres-, and five-hour daily peaks). However, we vary these assumptions in sensitivity studies. To satisty future load requirements, the utility can choose from among (1) conventional generating plants; (2) a TOU pricing resource (with scenario-based metering costs and price elasticities); ${ }^{2}$ (3) a technical conservation program (with a scenario-based cost of conserved energy (CCE)); and (4) a technical load management program (with scenariobased costs of conserved capacity $(\mathrm{CCC}))^{3}$

1 Implemeriting TOU pricing, running technical DSM programs, and constructing power plants are not mutually exclusive--i.e., if evaluated properly, it is likely that some of each will be selected as part of a utility's resource portfolio in real-world applications.

${ }^{2}$ The TOU-pricing resource is defined in the short run, reflecting differences in a utility's short-run operating costs. Another important pricing resource not considered in the study is the long run capacity supply cost--i.e., the long run marginal cost (LRMC) of generating electricity. We differentiate between the two types of resources in Section 3.1 and recommend in Section 6.3 that LRMC be investigated further as a pricing resource.

${ }^{3}$ Cost of conserved energy, usually expressed in $\mathrm{c} / \mathrm{kWh}$, is the amount necessary to save one $\mathrm{kWh}$ of consumption in a conservation program. Cost of conserved capacity, usually expressed in $\$ / \mathrm{kW}$, is the amount necessary to save one $\mathrm{kW}$ of demand in a load management program. 
The simulation results indicate that the financial attractiveness of TOU pricing is customer class-specific. For industrial customers, the degree of price-responsiveness to a TOU-pricing program depends critically on the types of industries served by the utility. However, the simulation results show that TOU pricing is cost-effective and more financially attractive than all other resource options even under assumptions of very low price-responsiveness. For residential customers, cost-effectiveness depends critically on the types of durables in use and, hence, the average amount of electricity consumption. Under conditions experienced by many electric utilities, TOU pricing is the most financially attractive resource available for the residential sector, as measured by benefit-cost ratios.

Besides CCE, an important determinant of the cost-effectiveness of a conservation program is its conservation load factor (CLF), and the relationship of that load factor to that of the system's. ${ }^{4}$ Higher CLFs result in greater financial attractiveness. The load management program is cost-effective under a wide range of assumptions about its CCC. More so than the other resource options, the financial attractiveness of the load management program is sensitive to assumptions about the length of the utility's peak. Assuming \$25 CCC, for example, the benefit-cost ratios for the load management program increase from 3.13 to 5.56 as the number of hours in the peak increases from one to five.

These results were obtained using a least-cost planning paradigm, using IRP principles. Three comments are appropriate. First, using least-cost, financial principles in utility planning does not imply that a "cost-effective" resource--or mix of them--is best for the financial position of the utility as measured by its income statement, balance sheet, and funds flow statement. Second, because we use financial least-cost--and not economic value--in evaluating candidate resources, we make no attempt to estimate the effects of price changes on the "value" of electricity services received by customers as measured by changes in consumers' surplus. Third, in a similar vein, we make no attempt to estimate the amount of technical electricity conservation induced by TOU pricing. As we suggest in Section 6, however, each of these three issues is worthy of further investigation.

\footnotetext{
The CLF of a conservation program is the ratio of average annual load savings (i.e., annual kWh savings divided by 8760 hours) to peak load savings.
} 


\section{INTRODUCTION}

\subsection{PURPOSE AND SCOPE OF THE STUDY}

The purpose of this study is to determine what factors make resource options more or less financially attractive to electric utilities in their planning processes. The resources under consideration include (1) cost-based pricing, (2) technical demand-side management (DSM) programs (i.e., conservation and load management programs), and (3) conventional generating plants. The reason for the study is that, in investigating measures to improve the efficiency of the electric power sector, an imbalance exists between research on (i) the financial costs and techinical characteristics of electricity-using durables and (ii) the costs of electricity used by these durables. The challenge of the study is to define a pricing resource that can be compared with technical DSM programs and generating plants. The results of the study are becoming increasingly important in the aftermath of the Energy Policy Act of 1992 (EPACT) which creates new institutions-and changes existing ones--to provide incentives for creation of a more competitive electric power industry.

Our objective in the study is not to prescribe specific rate schedules for individual electric utilities. Nor is our objective to compare the cost-effectiveness of different types of electricity rates with technical DSM programs and generating plants. Our objective is much more modest. It is to explore conditions under which cost-based pricing is more or less financially attractive to an electric utility than other resource options that it can choose from in satisfying electric load. In the study, cost-based pricing is defined as time-of-use (TOU) pricing, or rates that reflect the varying costs incurred by an electric utility in providing electricity at different times of the year. ${ }^{1}$ The output of the study is a matrix of results, showing the benefit-cost ratios of cost-based pricing, technical DSM programs, and generating plants under different assumptions about (1) number of customers and (2) financial characteristics of both the resource options and the electric utility.

\subsection{APPROACH USED IN THE STUDY}

To accomplish the objectives of the study, we simulate the resource selection process of a hypothetical utility over a 20 -year planning horizon. At first, we assume that the utility has the same generating mix as that of the 'average' U.S. electric utility, is neither a capacity-surplus nor a capacity-deficit utility, and its projected load is increasing at two percent per year, the average rate for the U.S. power sector. Its fuel costs are assumed to increase at the rates forecasted by the Energy Information Administration (1993). The system load factor is 0.60 , also the average for the U.S. power sector. In a sensitivity analysis, we assume three different load shapes (one-, three-, and five-hour

\footnotetext{
${ }^{1}$ TOU pricing refers to electricity rates that vary over the course of a year: hour-by-hour, day-by-day, or season-by-season. In this study, time-of-day (TOD) pricing (rates which vary over the course of a day), a specific form of the general class of TOU rates, is the same as TOU pricing because the hypothetical utility does not confront changing load curves by day, week, month, or season.
} 
daily peaks). Then, we change some utility-specific assumptions (e.g., assuming no real growth in fuel prices, a 0.50 system load factor, the existing generating mix is comprised of all combustion turbines) to see what effects these assumed conditions have on the relative financial attractiveness of the resource options.

The utility selects resources to minimize its revenue requirements-i.e., its total cost of providing electricity. However, because we assume that the utility pays the total cost of the TOU-pricing program and the conservation and load management programs, this "utility cost test" is the same as the "total resource cost test." 2 In satisfying load over the 20-year planning horizon, the utility can choose from among (1) conventional generating plants, (2) a TOU-pricing resource, and (3) technical DSM programs. Because TOU pricing and technical DSM programs vary by type of customer (i.e., service class), we define three types of customers: (1) low-volume customers; (2) medium-volume customers; and (3) high-volume customers.

The values of the financial and technical parameters defining the generating plants are based on the 'conventional wisdom' of constructing the plants today. The values of these parameters do not vary in the simulations. The hypothetical utility can select from among (1) steam coal, (2) combined cycle, and (3) combustion turbine plants. These plants vary from a high capital-low operating cost alternative to a low capital-high operating cost one. These generating options were selected to give the hypothetical utility an opportunity to fill as efficiently as possible the three main duty cycles in a utility's load: (1) base, (2) intermediate or cycling, and (3) peaking.

The TOU-pricing resource was defined by running a least-cost (to the utility), supply-only resource plan over the 20-year planning horizon using the three, aforementioned generating options. The peak-to-offpeak marginal costs for each hour of the day are calculated by SafePlan, the modeling tool used in the study. Using the peak-to-offpeak costs and the 'conventional wisdom' on customer responses to TOU rates, estimates of load reductions due to TOU rates were obtained. As sensitivity studies, we vary the amount of the load reduction using low and high price elasticities. In all cases, the reduction in peak $\mathrm{kWh}$ due to TOU pricing was totally offset by an increase in base kWh--i.e., the pricing resource is kWh-neutral. We also vary the additional amount of customer metering costs meeded to implement cost-based pricing: $\$ 2.00, \$ 5.00$ and $\$ 10.00$ per month per customer.

We also vary the values of parameters defining technical DSM programs. For conservation programs, we vary the cost of conserved energy (CCE) from $36 / \mathrm{kWh}$ to $56 / \mathrm{kWh}$ to $7 \mathrm{c} / \mathrm{kWh}$. For load management programs, we vary the cost of conserved capacity (CCC) from $\$ 25 / \mathrm{kW}$ to $\$ 75 / \mathrm{kW}$ to $\$ 125 / \mathrm{kW}$ on an annualized basis. Both types of programs are run over a 20-year period and reach maximum penetration in the market after 20 years. The "ramp rate" to achieve the maximum over 20 years is based on a

\footnotetext{
${ }^{2}$ Five tests are commonly used to determine the cost-effectiveness of DSM programs. Besides the two mentioned in the text, the participants test, the ratepayer impact measure, and the societal test are also used (California Public Utilities Commission and California Energy Commission, 1987).
} 
logistic curve.

Given these variants of a utility's load shape and behavioral and technical DSM resources, the simulation results lead to a matrix of benefit-cost ratios with multiple dimensions: (1) assumptions on the load shape of the utility, (2) three values of CCE and CCC for technical DSM programs, (3) three assumptions on customer metering costs for TOU pricing, (4) two different customer responses to TOU prices, and (5) varying assumptions on characteristics of the utility such as system load factor, real growth in fuel prices, and the mix of generating plants.

In this study, the calculation of benefit-cost ratios to determine relative costeffectiveness is based on the principles of integ ated resource planning (IRP), a paradigm used to determine the relative cost-effectiveness of demand and supply resource options. Using these IRP principles, we emulate procedures in a hypothetical utility's planning process. As such, the results do not indicate which resources--or combination of resources--will have the most favorable effect on the financial position of an electric utility as measured by its income statement, balance sheet, and funds flow statement. In fact, one of the primary recommendations of this study is to conduct such a comparative analysis. Also, because we take a practitioner's viewpoint, the results do not capture the "value" of resource options to customers as measured by consumers' surplus. Ours is a least-cost financial analysis--not an economic one.

\subsection{REMAINDER OF THE REPORT}

In Section 2, we provide more detail on characteristics of the hypothetical utility, including its generating mix, capacity position, load growth, and load factor. The TOUpricing resource is discussed in Section 3 . Besides the procedure that we use to define the resource, we also discuss its conceptual underpinnings and review the evidence on its effectiveness in shaping load. The technical DSM programs and generating options used in this study are defined in detail in Section 4. In Section 5, we first place the leastcost, financial framework used in this study in the context of broader economic approaches that could have been used. Then, we discuss the modeling procedures and simulation results. The relevance of the results for real-world utilities are discussed in Section 6. Also as part of this section, we suggest directions in which future research on cost-based pricing should proceed. 


\section{THE HYPOTHETICAL UTILTY}

\subsection{GENERATING MIX AND TSS CHARACTERISTICS}

U.S. electricity generation is dominated by conventional-steam generating plants. More than 70 percent of U.S. capacity is accounted for by conventional-steam technologies, burning coal, natural gas, and oil (Edison Electric Institute, 1993). Hydroelectric (12 percent) and nuclear steam (15 percent) are the other major generating types. The hypothetical electric utility defined in this study reflects the U.S. mix, normalized to 1000 megawatts (MW) of total capacity. In 1993, the base year for the study, the composition of total capacity is listed in Table 2.1. This mix was used for most of the simulations. However, to see the effects that generating capacity has on the relative cost-effectiveness of resource options, we assume that the 1,000 MW of existing generation is provided totally from combustion turbines in a sensitivity study.

Table 2.1

Existing Generating Plants and Capacities

\begin{tabular}{lr} 
Plant Type & Capacity (MW) \\
\hline Coal & 600 \\
Nuclear & 150 \\
Hydro & 100 \\
Combined Cycle (Gas) & 50 \\
Combustion Turbine (Gas) & 50 \\
Combustion Turbine (Oil) & 50 \\
$\quad$ Total & 1,000 \\
\end{tabular}

Real fuel prices increase at the rate forecasted by the Energy Information Administration (1993), provided in Table 2.2. Real growth in the price of natural gas is forecasted to be the greatest (3.2 percent per year), while the real price of nuclear fuel is not projected to grow at all. Similar to the existing generating mix, we assume no growth in fuel prices in a sensitivity study to see the effects that fuel-price increases have on the relative attractiveness of resource options.

\subsection{LOAD CHARACTERISTICS}

Given 1,000 MW of total capacity in 1993, an assumed reserve margin of 20 percent, and no deficit or surplus of capacity, peak demand in 1993 is 833 MW. Assuming the U.S. average annual projected peak growth rate of two percent, peak 
demand increases to $1,214 \mathrm{MW}$ in the year 2013, the 20th and last year of the planning horizon.

Table 2.2

Assumed Growth in Fuel Prices

1993-2013

\begin{tabular}{lllll}
\hline Period & Coal & $\begin{array}{c}\text { Natural } \\
\text { Gas }\end{array}$ & $\begin{array}{c}\text { Light } \\
\text { Oil }\end{array}$ & $\begin{array}{c}\text { Nuclear } \\
\text { Fuel }\end{array}$ \\
\hline $\begin{array}{l}1993 \text { Fuel Price Amounts } \\
\text { (\$1993 per 10 } 10^{\circ} \text { Btus) }\end{array}$ & 1.45 & 2.38 & 5.57 & 1.41 \\
$\begin{array}{l}1993-2013 \text { Growth in Fuel Prices } \\
\text { (Average annual growth rates) }\end{array}$ & 1.3 & 3.2 & 0.7 & 0.0 \\
\hline
\end{tabular}

SOURCE: Energy Information Administration (1993).

Increases in electric load occur, of course, because (1) new customers come on the system, (2) existing customers use more electricity on average, or (3) a combination of (1) and (2). For the sake of simplicity and without a loss of generality, we assume that new load growth occurs because new customers come on the system. The reason for this assumption is the way in which we define the TOU-pricing program and the technical DSM programs. This will be discussed in greater detail in Sections 3 and 4.

The hypothetical utility does not confront load curves that vary over the course of a week, month, season, or year. It confronts one fixed load curve with a system load factor of 0.60 , the average load factor of electric utilities in the United States (Edison Electric Institute, 1993). The assumed load consists of base, intermediate, and peak components. Although this system load configuration remains the same, the peak increases at the rate of two percent per year, reflecting average annual U.S. load growth. To see the effects of load factor assumptions on resource attractiveness, we assume a 0.50 system load factor in a sensitivity study.

Also for sensitivity purposes, we assume three load-shape scenarios: one-, three-, and five-hour peaks. In Figure 2.1, we show the annual load duration curves for these three load shapes. For any given load shape, the annual load duration curve is the product of the daily average load and 365 days. Therefore, the values in Figure 2.1 should be divided by 365 to obtain the daily load (e.g., 1825/365 yields the five-hour peak). We also assume that the base load remains constant in all simulations. Therefore, the intermediate load on the system changes with assumed changes in the length of peak 
periods. That is, the reduction in $\mathrm{kWh}$ consumption on the peak in going from a five-hour to a three-hour peak period affects only the intermediate load on the system--not the base load.

Figure 2.1

\section{Three Load Duration Curves for Sensitivity Analysis}

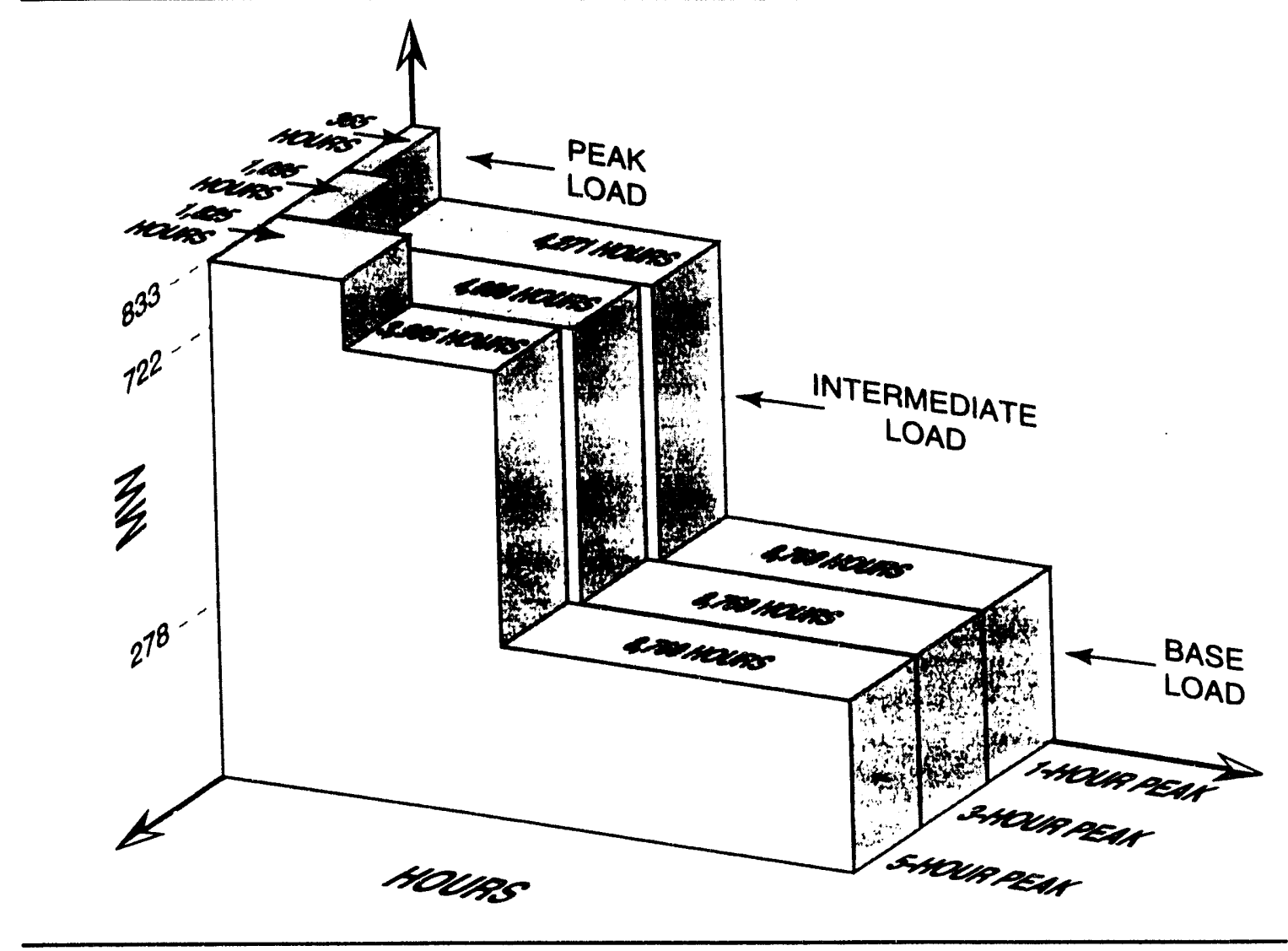

Finally, for each simulation we assume that the utility has only one customer class. This simplification does not detract from the objectives of the study. ${ }^{1}$ However, because of differences in technical DSM programs and the responsiveness of cost-based pricing targeted at different customer classes, we assume three different types of customers in three scenarios: (1) a low-volume customer class, (2) a medium-volume customer class, and (3) a high-volume customer class. For low-volume customers, we assume that the

${ }^{1}$ The one-class assumption does not impinge on the results because we also assume that the cost of serving each customer class--including capital costs--is fully reflected in the rates of each class--i.e., there are no cross-subsidies among customer classes. 
average customer consumes $10,000 \mathrm{kWh}$ of electricity per year, approximating the amount that the average U.S. residential customer consumes. In this scenario, there are 437,825 customers. $^{2}$ In the medium-volume customer scenario, we assume that the average customer consumes $60,000 \mathrm{kWh}$ per year, approximating the average amount consumed by U.S. commercial customers. In this case, there are 72,970 customers. In the high-volume case approximating the average U.S. industrial customer, $1,870,000 \mathrm{kWh}$ of average consumption results in 2,340 customers.

${ }^{2}$ Given 833 MW of peak load in 1993 and a 0.60 load factor, the hypothetical utility sells $4,378.3 \mathrm{GWh}$ of electricity in 1993. Dividing sales by the consumption of the average customer yields 437,835 customers. 


\section{TOU PRICING AS A CANDIDATE RESOURCE}

\subsection{CONCEPTUAL UNDERPINNINGS}

Historically, U.S. electric utilities used backward-looking accounting criteria to design rates, usually accomplished in two steps. In the first step, the typical utility would use a historical test year (or years) of accounting data--and their relationships--to determine its overall revenue requirements. The procedure was to set total revenues at a level sufficient to recoup operating and maintenance expenses, taxes, depreciation, and compensation to capital contributors (e.g., debt- and equity-holders).

In the second step, the utility would determine its rate structure. Typically, it would accomplish this by assigning total costs estimated in the first step to its customer classes on the basis of costs that could be directly assigned (e.g., industrial metering costs) and those that were more appropriately assigned by function (e.g., number of customers, amount of energy). Once costs were assigned to classes, it was a simple matter to design rates because they were typically invariant to the amount of consumption or, in many cases, even declining as the amount of consumption increased.

This historical approach to ratemaking does not account for the unique characteristics of electicicity production and consumption. That is, electricity cannot be stored economically and its use varies by time of day, week, and season. The importance of reflecting this difference in rates has long been recognized and applied in Western Europe, and is one of the pillars of modern U.S. ratemaking. ${ }^{1}$

In this study, we use these modern ratemaking principles to define the pricing resource that we compare with technical DSM programs and generating plants. Modern ratemaking, however, is more complex than the historical approach, more forward-looking and based more on marginal than average costs. Similar to the historical approach, there are two types of costs reflected in rates using the modern approach: (1) operating expenses (i.e., the short-run cost) and (2) capacity costs (i.e., the long-run cost). Unlike the historical approach, however, operating and capacity costs are reflected in rates more on the basis of expected future conditions--rather than a historical test year--five, ten, or even 20 years from the time rates are set.

In practice, the difficulty with reflecting operating costs in rates is that, as mentioned above, these costs are not the same over the course of a day, week, or season. They typically vary by time-of-use--i.e., the short-run marginal cost of providing electricity during peak hours is generally higher than providing the same amount of electricity during offpeak hours because of differences in the types of generating plants used during the two periods. Modern ratemaking reflects these cost differences in rates

\footnotetext{
${ }^{1}$ Motivated by the seminal work of Boiteux (1949). France, for example, has been a leader in implementing TOU tariffs. Electricite de France developed marginal cost price schedules for high-voltage users as early as 1955, implementing voluntary industrial TOU rates for industrial customers in 1958. The tariff became mandatory a decade later.
} 
varying by time of use. At the extreme, experiments with real-time pricing indicate that it is technologically feasible to reflect actual production costs in rates with lead times to customers as short as 24 hours. $^{2}$

Reflecting the costs of additional or replacement capacity in modern ratemaking is also forward-looking. Referred to as long-run marginal-cost pricing, this portion of the tariff reflects the costs of expected new capacity construction. In practice, the projection of capacity requirements is variable depending on the utility. It could be based on a projection of capacity needs as short as five or as long as 20 years into the future. Also in practice, this portion of the rate typically is added to the short-run, operating-cost portion as a demand charge $(\$ / \mathrm{kW})$ to determine the total rate by hour, week, or season. The operating-cost portion, of course, is typically expressed in $₫ / \mathrm{kWh}$.

Because of the objective of this study, we did not divide the TOU pricing resource into an operating and capacity portion. Rather, we used the short-run marginal cost as the basis for defining the pricing resource. As discussed in Section 2, we developed different scenarios for consumption by time of day: one-, three-, and five-hour peaks. We then developed an optimal supply-side plan over a 20-year planning horizon to estimate the relative (marginal) cost of providing electricity by time of day. Using the conventional wisciom on responsiveness of different customer classes to pricing by time of day, we estimated the load-shape effects of implementing TOU pricing. The pricing structure was intended to reflect exclusively the marginal difference in operating costs between peak and offpeak periods--i.e., the short-run marginal cost. We made no attempt to measure the capacity benefits of TOU rates.

Quantifying both the short-run energy--or peak-load--effects of implementing TOU pricing and the long-run base-load capacity effects would likely match the pricing resource defined in this study more closely with the technical conservation and load management programs defined in the study. However, this comparison is left for other studies.

We now turn to the conventional wisdom on customer responses to TOU pricing by customer class.

\subsection{EVIDENCE OF TOU PRICING'S EFFECTIVENESS IN SHAPING LOAD}

Customer response to TOU rates can be shown in two ways: (1) load shape impacts for the peak, shoulder, and offpeak periods and (2) price elasticies for the peak, shoulder, and offpeak periods, both own- and cross-price elasticities. Given financial and load information on the utility, load shape impacts are readily convertible to price elasticities. The reverse is also true. In the discussion that follows, we will use both types of responsiveness measures. And, in defining the pricing resource for this study, we will provide both load-shape impacts and elasticities for peak and offpeak periods.

\footnotetext{
${ }^{2}$ For a recent survey of real-time pricing programs in the U.S. electric power sector, see Mak and Chapman (1993).
} 
There are five important factors that must be considered when discussing the responsiveness of customers to TOU rates:

- voluntary vs. mandatory TOU programs

- short-vs. long-run responses

- demographic and customer characteristics (e.g., types of durables and manufacturing processes, climate, income)

- length of peak period

- ratio of peak to offpeak prices

Each of these effects will be addressed to varying degrees in the discussion that follows.

\subsubsection{Low-Volume Customers}

Evaluations of TOU pricing programs run by U.S. utilities are good initial sources of information on customer responses to TOU rates. For example, the Potomac Electric Power Company estimated that on-peak $\mathrm{kWh}$ were reduced by 3.0 percent upon implementing a mandatory TOU tariff, offset in part by a 1.5 percent increase in offpeak consumption. Pacific Gas and Electric Company reported a 19.1 percent peak reduction offset partially by an 18.4 perecent offpeak increase. ${ }^{3}$ These responses, however, are specific to the unique circumstances of these two utilities.

The U.S. residential TOU pricing experiments are also important sources of information on low-volume customer response to TOU rates, providing the most systematic look at changes in energy and demand from implementing TOU pricing. ${ }^{4}$ The results of these experiments suggest that TOU pricing is effective in inducing a shift in kWh electricity consumption from peak to offpeak periods. However, there was enough variability across experiments in both the types of utilities involved (e.g., warm-climate, summer-peaking vs. cold-climate, winter-peaking) and the types of experiments conducted and analyses performed (e.g., single vs. multiple-rate experiments, experimental design) to question the consistency of response to the experimental rate designs.

To address the consistency problem, Caves, Christensen, and Herriges (1984) pooled data from five experiments, accounting for household characteristics, dwelling types, climate, and the penetration of electricity-using equipment in estimating responses to TOD tariffs. Their results, shown in part in Table 3.1, show a consistent response by low-volume customers to TOU rates. For an average customer, the elasticity of substitution of offpeak for peak electricity is 0.14 , implying that 1.4 percent of peak-period

\footnotetext{
${ }^{3}$ As cited in Faruqui et al. (1991).
}

${ }^{4}$ In 1975, ten experiments were initiated in the states of Arizona, Arkansas, Connecticut, California, New Jersey, Ohio, Wisconsin, Vermont, Michigan, and New York. Six more were added the following year, including ones in California, North Carolina, Oklahoma, Puerto Rico, Rhode Island, and Washington. Summaries of results of the experiments are provided in Hill (1990) and Faruqui and Malko (1983). 
consumption is shifted to offpeak periods if the ratio of peak to offpeak prices increases 10 percent. Characteristics of the tariff itself (e.g., peak-to-off-peak price ratio and length of the peak period), the amount of household electricity consumption, the types of electricity-using equipment, and the weather were found to be important determinants of responsiveness to the rates.

\begin{tabular}{|c|c|c|c|}
\hline \multicolumn{4}{|c|}{$\begin{array}{l}\text { Table } 3.1 \\
\text { Responses to U.S. Residential TOD Rates" } \\
\text { Summer Months } \\
\text { Different Appliance and Weather Scenarios }\end{array}$} \\
\hline \multirow{2}{*}{ Weather } & \multicolumn{3}{|c|}{ Appliance Saturation } \\
\hline & None & Typical & All \\
\hline $\begin{array}{l}\text { Cool } \\
\text { Typical } \\
\text { Hot }\end{array}$ & $\begin{array}{l}0.09 \\
0.07 \\
0.05\end{array}$ & $\begin{array}{l}0.12 \\
0.14 \\
0.15\end{array}$ & $\begin{array}{l}0.16 \\
0.21 \\
0.25\end{array}$ \\
\hline
\end{tabular}

SOURCE: Caves, Christensen, and Herriges (1984), Table 8, p. 198.

${ }^{a}$ Response measured by the elasticity of substitution between peak and off-peak electricity consumption.

The pooled model was designed customers on mandatory TOU rates because the five utilities included in the pooling were either on mandatory TOU rates or were given incentives to prevent them from self-selecting out of the experiments. Estimating the load impacts of customers on voluntary TOD rates is more difficult because of the additional problem of accounting for the decision to opt for the tariff.

Evidence on the load effects of voluntary TOD rates is sketchy. In one study, Caves, Herriges, and Kuester (1989) analyzed a voluntary residential TOU tariff offered by Pacific Gas and Electric Company on an experimental basis. In the study, 1,000 highvolume (more than 1,000 $\mathrm{KWh}$ per month) volunteers were evaluated over the 1983-84 period. The study concluded that customers who voluntarily select the tariff have approximately the same peak-period percentage consumption as the average residential household on PG\&E's system. Furthermore, responsiveness of customers voluntarily opting for the tariff is greater than that for customers on mandatory TOU tariffs. The 0.37 elasticity of substitution between offpeak and peak consumption is significantly larger than that of, for example, the 0.14 "typical" elasticity for the five utilities in the pooled study discussed above (Table 3.1). And, treating customers on PG\&E's voluntary tariff as if they 
were on a mandatory one, controlling for all conditioning variables, results in a lower elasticity of substitution ( 0.18 vs. 0.37$)$. Thus, the study suggests that more peak to offpeak response is provided by a voluntary customer, even if that customer consumes electricity under the same conditions as a similar customer on a mandatory TOD tariff.

\subsubsection{Medium- and High-Volume Customers}

As with low-volume customers, many utilities implementing TOU rates for mediumand high-volume customers have evaluated customer responses to the TOU tariffs. For example, Southern California Edison's largest customers (i.e., more than five MW of demand) reduced onpeak summer demand by 7.5 percent in response to mandatory TOU rates. ${ }^{5}$ Similar to low-volume customers, it is difficult to transfer the experience of one utility to others.

The most comprehensive study on medium- and high-volume customer response to TOU rates was conducted by Park and Acton (1984), and follwed up three years later (Acton and Park, 1987). In the studies, customer response to mandatory TOU rates were estimated using data from ten U.S. utilities which included more than 6,000 medium-and high-volume customers. The results of the study are summarized in Table 3.2. The estimated change in relative peak load upon introduction of TOU rates was less than one percent, with commercial customers more unresponsive $(0.29$ percent) than higher-voltage users (1.03 percent). As shown in Footnote ' $a$ ' of Table 3.2, relative peak $\mathrm{kWh}$ consumption in any given month is defined as the ratio of average $\mathrm{kWh}$ consumption during peak periods to average $\mathrm{kWh}$ consumption during all weekday hours. The change in relative peak $\mathrm{kWh}$ consumption is the difference between a current and prior year's monthly consumption.

Although the average response for high-volume customers is fairly small in the two studies, responsiveness varies significantly by industry. In the Acton and Park work, for example, wood products showed the largest response to the introduction of TOU rates with a 6.38 percent change in relative consumption.

Generally, energy-intensive, mechanical production processes producing discrete loads respond more to TOU pricing than industries with continuous production processes. In studies of U.S. industries, wood products and cement production generally show the largest short-run responses to TOU rates. In longer run studies of both French and British industry, cement production exhibits the largest response to TOU rates. In both countries, cement producers reduce load by as much as 50 percent during weekday peak periods and, on weekends when only off-peak tariffs apply, they retain an almost constant load at the level of highest off-peak, weekday consumption. The distinguishing characteristic of these industries is their ability to curtail operations during peak periods or switch production from peak to off-peak periods in response to the tariffs. Continuous process industries such as motor vehicle production and petroleum refining, on the other hand, cannot curtail production and, therefore, exhibit very little response to TOU rates,

\footnotetext{
${ }^{5}$ As cited in Faruqui et al. (1991)
} 
unless individual plants have their own sources of power that can be used during peak periods.

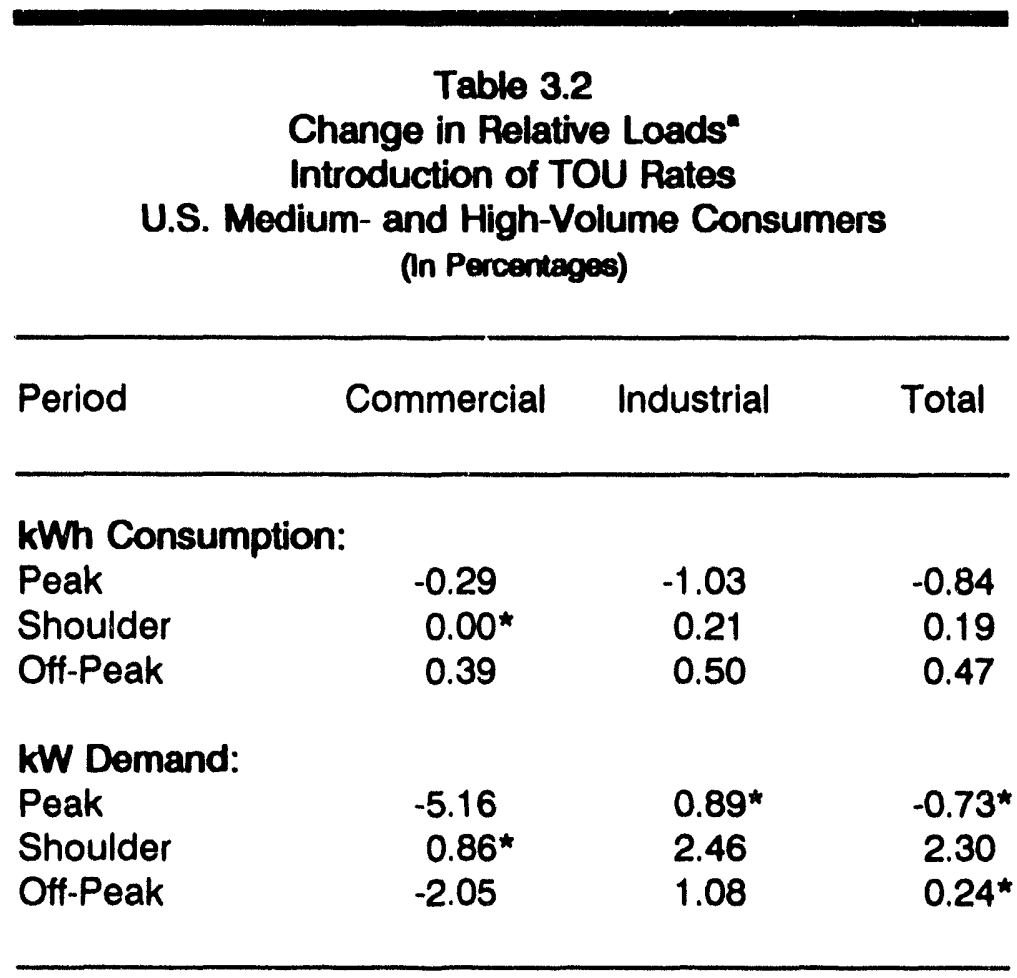

SOURCE: Acton and Park (1987), Tables 12 and 14.

"Statistically insignificant.

'Relative kWh consumption for any of the three periods is defined as the average $\mathrm{kWh}$ consumption during the period expressed as a percentage of average $\mathrm{kWh}$ consumption during all weekday hours. Similarly, relative KW demand for any of the three periods is the ratio of maximum hourly demand during any of the periods to the average hourly $\mathrm{kWh}$ consumption during that period. Both $\mathrm{kWh}$ consumption and $\mathrm{kW}$ demand were measured as changes from the preceding year.

\subsection{BENEFITS AND COSTS OF TOU PRICING IN THIS STUDY}

In the previous two subsections, we discussed the principles of modern ratemaking and the evidence on customer responses to TOU rates. We use this as a foundation to define boundaries for the benefits of implementing TOU pricing--i.e., reduced loads resulting in avoided energy and capacity costs for the utility. We also define boundaries for the costs of implementing TOU pricing--i.e., the incremental capital costs (i.e., meters that can monitor electricity consumption by time of day) and operating costs (i.e., administrative costs) associated with moving from an accounting-based pricing system to a marginal cost-based one. 
As shown earlier, customer responses to TOU rates are very sensitive to characteristics of customers. With the exception of numbers of customers by class, we have not characterized customers in this study because our objective is to isolate factors that make various resources more or less financially attractive to electric utilities. We accomplish this by bounding the values of important parameters, including customer responses to the introduction of TOU rates. These boundaries, however, are consistent with the conventional wisdom on responses to TOU rates.

The values of responses are summarized in Table 3.3. The average response of residential customers in the Caves, Christensen, and Herriges (1984) study is contained within the two extremes of the low- and high-elasticity cases. The same is true for the average value of the Park and Acton (1987) studies of higher-volume customer responses.

\section{Table 3.3 \\ Assumed Responses to TOU Pricing \\ Load Shape Changes and Own-Price Elasticities \\ Three Customer Classes}

Customer Class

Elasticity Scenario

Load-Shape Impact (\%)

Own-Price Elasticity

Peak Offpeak

Peak Offpeak

Low-Volume Customers

Low Elasticity

High Elasticity

Medium-Volume Customers

Low Elasticity

High Elasticity

High-Volume Customers

Low Elasticity

High Elasticity
$-10.0$

$-20.0$

$-0.58$

$-1.78$

$-0.58$

$-3.00$

$$
+3.60
$$

$+7.20$

$-.083$

$-.165$

$-.031$

$-.062$

$+0.36$

$+0.72$

$-.005$

$-.015$

$-.002$

$-.006$

We did not distinguish between short- and long-run responses in characterizing the TOU pricing resource for this study. The responses shown in Table 3.3 were applied uniformly to each year of the 20-year planning horizon. Therefore, to the extent that customers change their consumption habits over time, purchase different types of durables, or change the process by which they use energy in response to TOU rates, we underestimate the effects of the tariffs. 
Also, in characterizing responses to the tariffs, we assume that their effects are kWh-neutral. That is, for every kWh "saved" on-peak, an extra kWh is consumed offpeak in the base period. Although there is generally not a one $\mathrm{kWh}$-for-one $\mathrm{kWh}$ response, this type of behavior is consistent with what occurs in real-world applications. We characterize it in Figure 3.1.

Figure 3.1

Load-Curve Effects of TOU Pricing

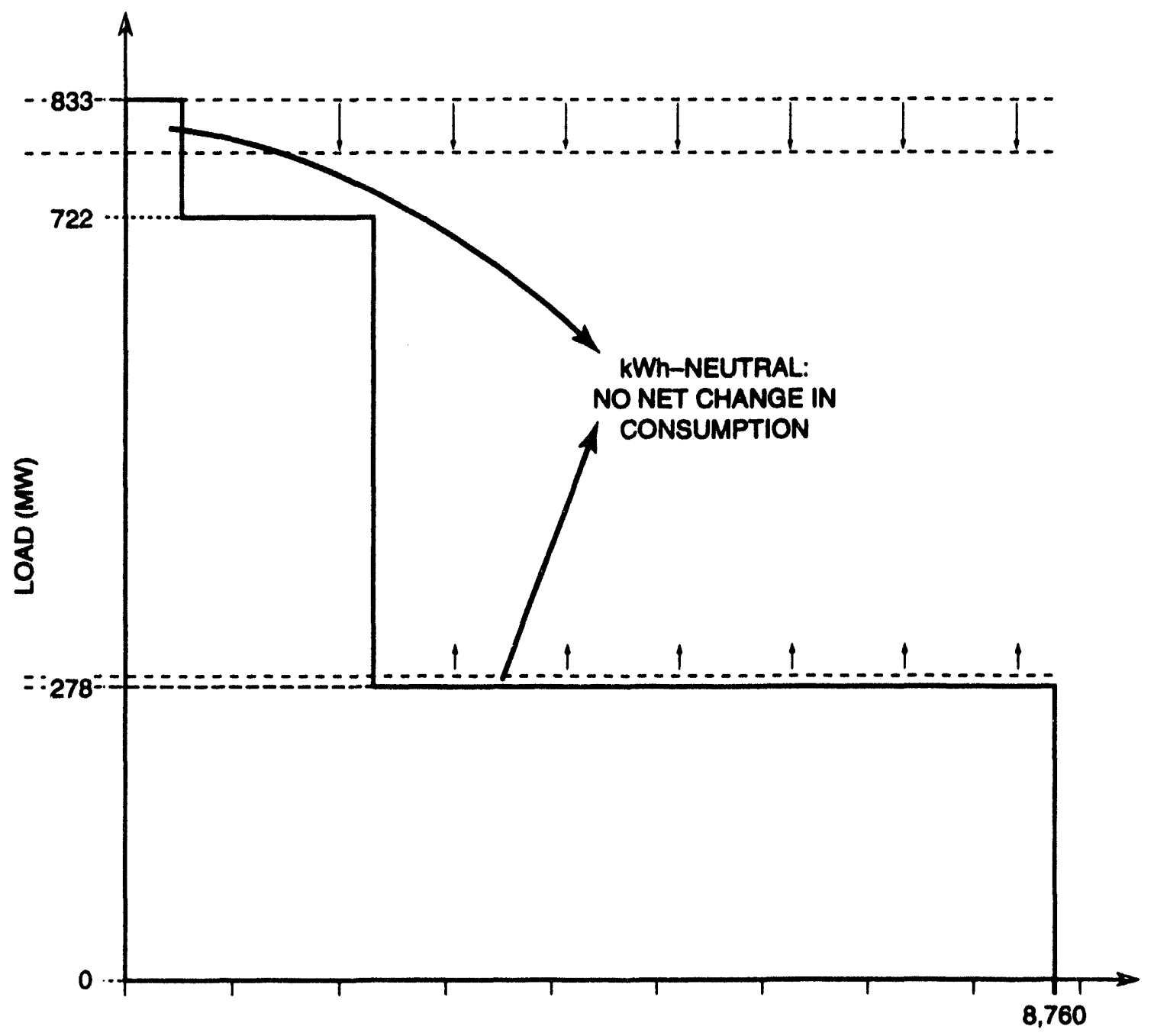

HOURS 
The costs of implementing TOU pricing are the incremental capital and operating costs incurred by the utility in switching from standard rates to those based on time of use. We summarize the incremental costs in Table 3.4. The capital cost is the cost of a standard electronic meter that measures consumption by time of day. Reflecting realworld conditions, we assume that the meter is more costly for higher-volume (and highervoltage) customers because those meters have the capability of measuring peak demand. For small-volume customers, we assume that the meters can only measure energy consumed during peak and offpeak periods. We assume the same capital cost for meters used by medium- and high-volume customers. High-volume customers require two of them, assuming that the average high-volume customer's facilities are divided between administration and operations. Note also that we abstract from the problem of writing off the costs of existing meters that typically have useful lives of 30 years.

Table 3.4

Metering Costs

Three Customer Classes

Category

Customer Classes

Low-Volume Medium-Volume High-Volume

Capital Cost of TOU Meters

$\$ 250.00$

$\$ 400.00$

$\$ 800.00^{\mathrm{a}}$

Annual Carrying Charge (@9\%)

$\$ 22.50$

$\$ 36.00$

$\$ 72.00$

Monthly Capital Carrying Charge

$\$ 1.88 \quad \$ 3.00$

$\$ 6.00$

Monthly Administrative Expenses

$\$ 1.50$

$\$ 3.00$

$\$ 4.50$

Additional Monthly Expenses

$\$ 3.38$

$\$ 6.00$

$\$ 10.50$

assumes two $\$ 400$ meters

Using a 9-percent annual capital carrying charge rate and dividing by 12 months, the monthly capital metering costs for low-, medium-, and high-volume customers are $\$ 1.88, \$ 3.00$, and $\$ 6.00$, respectively. Assuming additional monthly TOU administrative costs of $\$ 1.50, \$ 3.00$, and $\$ 4.50$ results in TOU customer costs ranging from $\$ 3.38$ to $\$ 10.50$. Similar to customer responses to TOU rates, TOU metering costs are dependent on specific characteristics of the utility and its customers (i.e., size of the utility, quantity discounts for meters). Therefore, we use $\$ 2.00, \$ 5.00$, and $\$ 10.00$ metering cost scenarios for each of the customer classes in the simulations described in the next section. 


\section{OTHER CANDIDATE RESOURCES}

\subsection{TECHNICAL DSM PROGRAMS}

We quantify the parameters defining three conservation programs and one load management program in Table 4.1. The values of the parameters are averages, based

Table 4.1

Key Variables for Technical DSM Programs

\begin{tabular}{|c|c|c|c|c|c|}
\hline Program & $\begin{array}{c}\text { Maximum } \\
\text { Demand } \\
\text { Savings } \\
\text { (MW) }\end{array}$ & $\begin{array}{l}\text { Maximum } \\
\text { Energy } \\
\text { Savings } \\
\text { (GWh/Year) }\end{array}$ & $\begin{array}{l}\text { Conservation } \\
\text { Load } \\
\text { Factor } \\
(\%)\end{array}$ & $\begin{array}{l}\text { Maximum } \\
\text { Participation } \\
\text { (\%) }\end{array}$ & $\begin{array}{l}\text { Program } \\
\text { Costs }\end{array}$ \\
\hline \multicolumn{6}{|l|}{ Low-Volume: } \\
\hline Conservation & 65 & 341 & 60 & 78 & $36 / \mathrm{kWh}$ \\
\hline Conservation & 65 & 341 & 60 & 78 & $5 c / k W h$ \\
\hline Conservation & 65 & 341 & 60 & 78 & $7 c / k W h$ \\
\hline \multicolumn{6}{|l|}{ Medium-Volume: } \\
\hline Conservation & 130 & 683 & 60 & 78 & $36 / k W h$ \\
\hline Conservation & 130 & 683 & 60 & 78 & $56 / k W h$ \\
\hline Conservation & 130 & 683 & 60 & 78 & $7 € / k W h$ \\
\hline Load Management & 132 & NA & NA & 78 & $\$ 25 / \mathrm{kW}$ \\
\hline Load Management & 132 & NA & NA & 78 & $\$ 75 / \mathrm{kW}$ \\
\hline Load Management & 132 & NA & NA & 78 & $\$ 125 / \mathrm{kW}$ \\
\hline \multicolumn{6}{|l|}{ High-Volume: } \\
\hline Conservation & 130 & 683 & 60 & 78 & $3 \notin / \mathrm{kWh}$ \\
\hline Conservation & 130 & 683 & 60 & 78 & $5 \& / \mathrm{kWh}$ \\
\hline Conservation & 130 & 683 & 60 & 78 & $7 \notin / k W h$ \\
\hline
\end{tabular}

After 20 years of running the program

NA-Not applicable

on the conventional wisdom of utilities' experiences with running conservation and load management programs. The low-, medium-, and high-volume customer classes were defined in Section 2. Maximum customer participation for the four programs is not 
reached untll 20 years after they are implemented. The "ramping" of the programs to maximum participation over the 20-year is characterized in Figure 4.1. The programs begin with two percent participation in the first year and "ramp up" to 78 percent maximum participation in their 20th year of operation. The savings over that period for the low-volume conservation program increase from $13 \mathrm{GWh}$ in the first year to $341 \mathrm{GWh}$ in the 20th year. Corresponding energy savings for the medium- and high-volume conservation programs are $17 \mathrm{GWh}$ ramping to $683 \mathrm{GWh}$. For the load management program, savings increase from $4 \mathrm{MW}$ in the first year to $132 \mathrm{MW}$ in the 20th year.

Figure 4.1

'Ramp Rate' for Technical DSM Programs

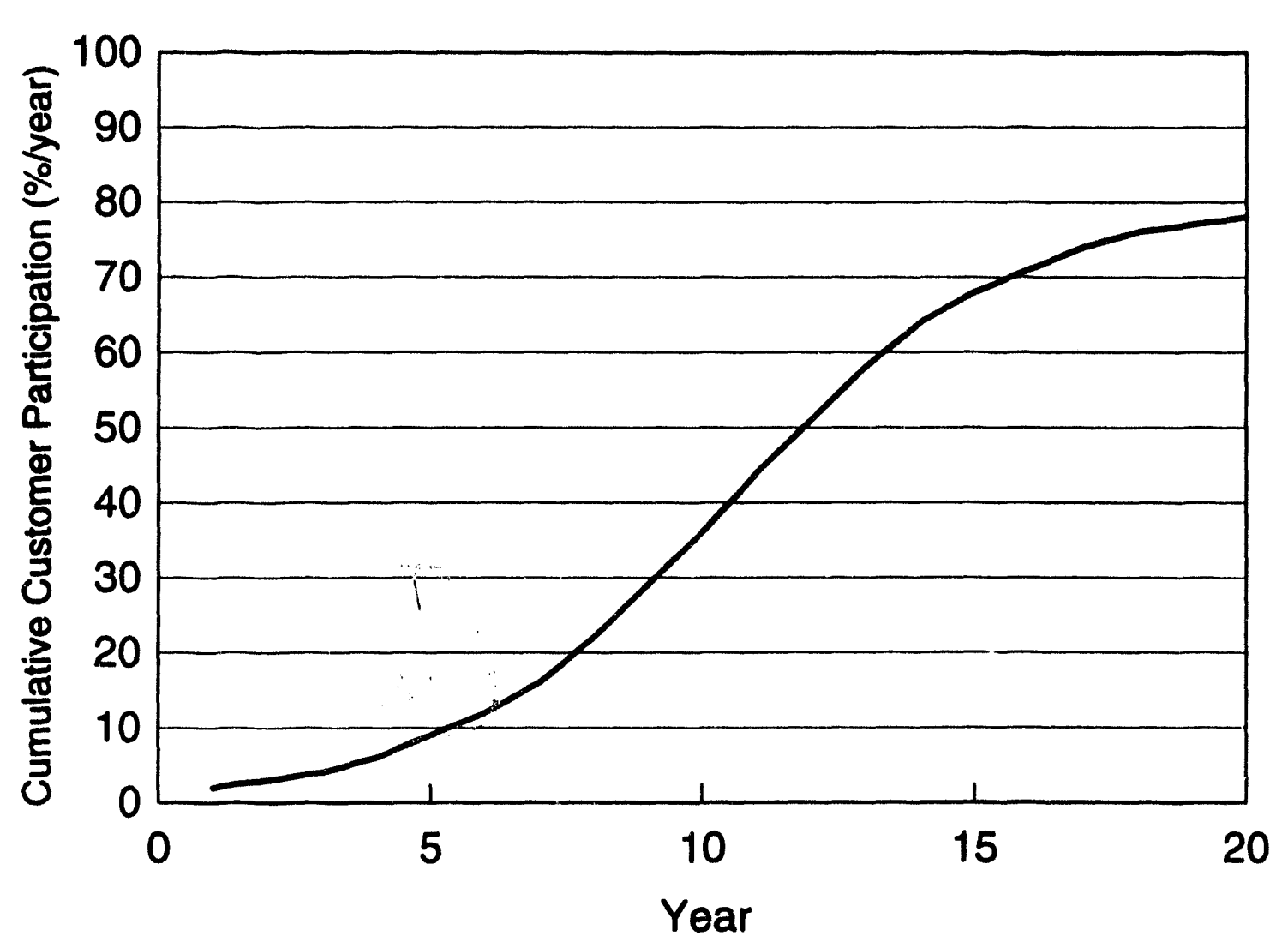

To simplity the analysis, ramping to the maximum energy and capacity savings for the four DSM programs is fixed over the 20-year planning horizon as shown in Table 4.1 and Figure 4.1. That is, the level and rate of ramping is assumed invariant to growth in peak demand. Clearly, peak demand grows because new customers are added to a utility's system or existing customers increase their average demand. In most cases, this growth would change the types of DSM programs offered by the utility to its customers. 
However, capturing these changes in the technical DSM programs of the current study would complicate the analysis without resulting in offsetting insights into the relative costeffectiveness of resources. In a real-world setting, the technical DSM programs defined in this study are equivalent to programs targeted at customers existing in the base year who do not increase their average peak demand or energy consumption over the planning horizon.

As shown in Table 4.1, three different program cost scenarios are assumed for each of the four programs, providing reasonable boundaries for what is likely to exist in real-world applications. The conservation load factor (CLF) for the conservation programs is initially set at 0.60 . However, to see the effect that the assumed CLF has on the costeffectiveness of conservation programs, we vary it from 0.2 to 0.8 in a sensitivity study. Also, to see the interactive effects of the system load factor and CLF, we vary the CLF from 0.2 to 0.8 assuming a 0.50 system load factor. The results of the sensitivity studies are presented in Section 5. As shown in Table 4.1, although calculable, the CLF is not relevant to load management programs.

The effects of the conservation and load management programs on the hypothetical utility's load duration curve are shown individually in Figure 4.2. For the conservation program, the reductions in load on shoulder and offpeak hours are not as great as those occurring during peak hours, and the shoulder and offpeak reductions depend on the CLF. Given a reduction in peak demand from a conservation program, the higher the value of the CLF, the larger the reduction in shoulder and offpeak demand. In contrast to the conservation program, running a load-management program only affects demand during peak hours.

\subsection{GENERATING PLANTS}

In Table 4.2, we present the values of key financial and technical variables for the three generating plants that the hypothetical utility can construct to satisfy future load. The values of the variables are 'conventional wisdom' for those plants built today in the Midwestern part of the United States. The plants were selected because they provide the hypothetical utility a minimum of one plant to choose from to perform the three work loads in a power system: (1) the coal plant for base load; (2) the combined cycle plant for intermediate load; and (3) the combustion turbine for peak load. The construction expenditure profile for each of the candidate generating plants is also conventional wisdom for a Midwestern plant. The growth in fuel prices over the 20-year planning horizon is that forecasted by the Energy Information Administration and the same projections used for existing generating plants (Table 2.2). 
Figure 4.2

Loed-Curve Ellects

Conservation and Load Management Programs

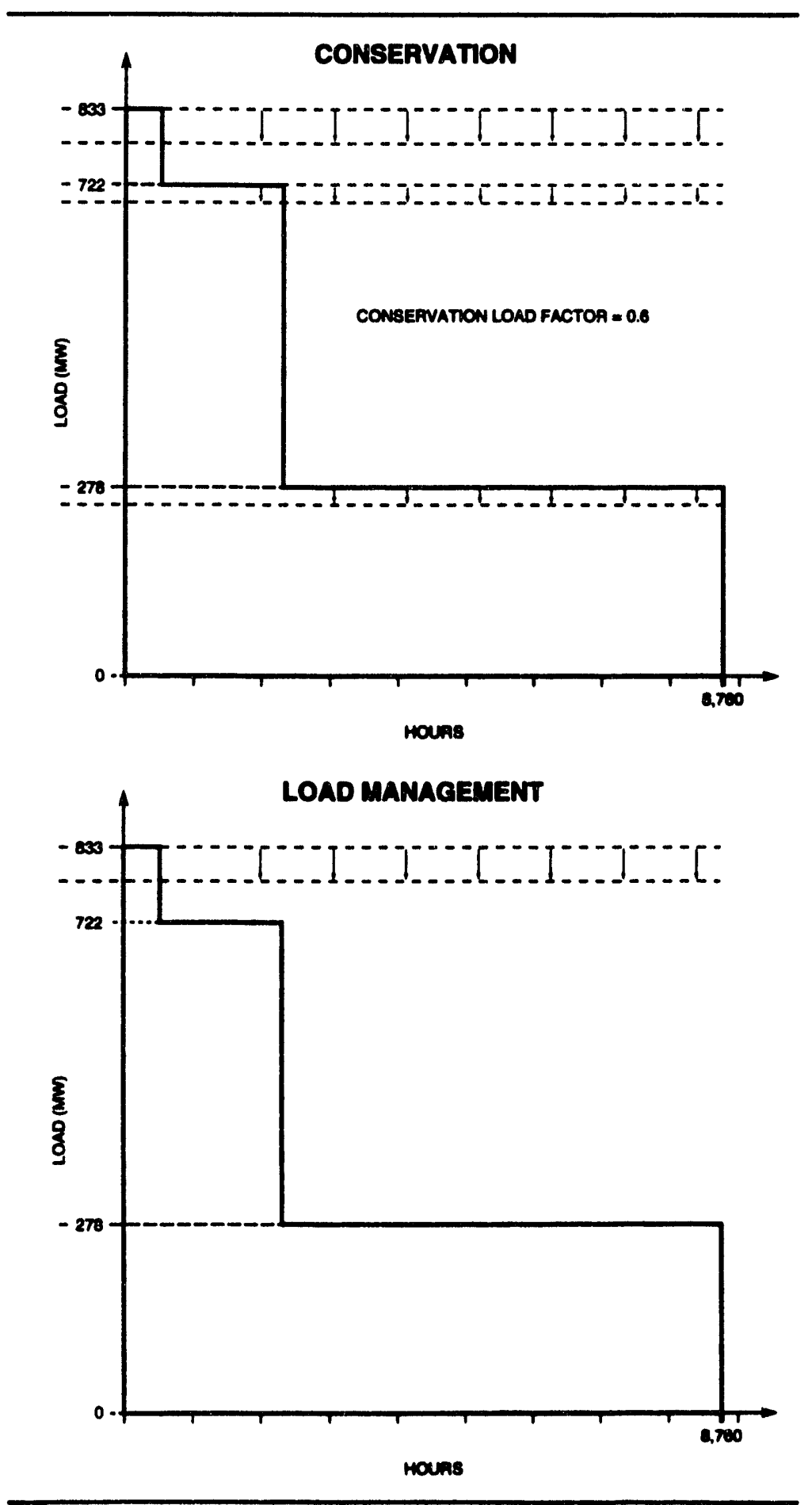


Table 4.2

Key Variables for Candidate Generating Plants

\begin{tabular}{|c|c|c|c|}
\hline & $\begin{array}{c}\text { Steam } \\
\text { Coal }\end{array}$ & $\begin{array}{l}\text { Combined } \\
\text { Cycle }\end{array}$ & $\begin{array}{l}\text { Combustion } \\
\text { Turbine }\end{array}$ \\
\hline $\begin{array}{l}\text { Fuel Type } \\
\text { Capacity (MW) } \\
\text { Cost (\$/kW) } \\
\text { Variable O\&M (\$/MWh) } \\
\text { Fixed O\&M (\$/kW) } \\
\text { Heat Rate (Btus/kWh) } \\
\text { Availability Rate (\%) } \\
\text { Construction Period (Years) }\end{array}$ & $\begin{array}{l}\text { Coal } \\
200 \\
1,512 \\
7.00 \\
30.30 \\
10,060 \\
85 \\
6\end{array}$ & $\begin{array}{l}\text { Gas } \\
50 \\
590 \\
2.20 \\
8.40 \\
8,140 \\
85 \\
4\end{array}$ & $\begin{array}{l}\text { Gas } \\
50 \\
340 \\
5.00 \\
0.50 \\
13,100 \\
85 \\
2\end{array}$ \\
\hline \multicolumn{4}{|c|}{$\begin{array}{l}\text { Construction Expenditure Profile(\%): } \\
\text { Year (Before on line) }\end{array}$} \\
\hline $\begin{array}{l}1 \\
2 \\
3 \\
4 \\
5 \\
6\end{array}$ & $\begin{array}{l}20 \\
25 \\
30 \\
13 \\
9 \\
3 \\
\end{array}$ & $\begin{array}{l}38 \\
37 \\
13 \\
12\end{array}$ & $\begin{array}{l}75 \\
25\end{array}$ \\
\hline Total & 100 & 100 & 100 \\
\hline
\end{tabular}

SOURCES: Electric Power Rese rch Institute (1989), Department of Energy (1991/1992), and Energy Information Administration (1993). 


\section{COST-EFFECTIVENESS OF RESOURCE OPTIONS}

\subsection{FRAMEWORK FOR ANALYSIS}

In determining the relative cost-effectiveness of resource options, the incremental costs of the options are compared with their incremental benefits. The question becomes: What are the "correct" costs and benefits to be used in the calculus? The answer would probably differ, depending on the perspective of the respondent.

From a practitioner's financial perspective, changes in the operating conditions of the utility dominate cost-effectiveness calculations. These changes include the effects of candidate resources on load shape, revenues, and costs. Changes in costs can occur in both the short and long run. In the short run, changes include additional metering costs, increased administrative costs, and the energy savings due to lower fuel costs. In the long run, capacity savings are an important benefit.

Although these financial effects are part of the economic perspective, they are only one portion of it. Consider TOU pricing, for example. From an economic perspective, moving to TOU rates from ones based on average costs has two important effects. First, based on welfare criteria, TOU pricing improves the efficiency of the power system. The efficiency improvements are measured by changes in producers' and consumers' surplus. The second effect is related to equity: higher costs of electricity during peak hours are borne by customers consuming during peak hours.

In practice, the evidence suggests that the practitioner's and economic paradigms are slowly converging. Prior to the 1980 s, utilities practiced what is commonly referred to as least-cost planning, a financial planning paradigm in which utilities minimized supply costs given forecasts of their customers' load growth. This forecasted growth was exogenous in utility planning. Because there is a direct relationship between costs and prices in utility ratemaking, cost minimization is equivalent to price minimization.

As more and more utilities began to intervene on the customer's side of the meter by running DSM programs in the 1980s, this least-cost/least-price planning paradigm evolved into minimization of the cost of electricity services. In response to this demandside emphasis, the California Public Utilities Commission and California Energy Commission developed a set of perspectives from which to measure the costeffectiveness of utility-run DSM programs: (1) the utility exclusively and (2) participants, non-participants, and their total (which may or may not include societal effects). The resulting planning paradigm--integrated resource planning (IRP)--is the combination of traditional least-cost supply planning and demand-side planning. By emphasizing the total resource cost test in this paradigm, the industry's and regulator's focus switched from least-cost supply plans to least-cost electricity service plans.

In developing cost-effectiveness perpsectives of DSM programs and

${ }^{1}$ California Public Utilities Commission and California Energy Commission (1987). 
recommending various cost and benefit categories to include in the perspectives, the authors of "California standard practice" acknowledged the limitations of the tests. An important one is their static nature: the tests do not account for price changes and their effects on customer behavior, including the snap-back or take-back effects associated with improved energy efficiency.

Recognizing this deficiency in California standard practice, several authors (e.g., Hobbs, 1991; Borlick, 1994; Braithwait and Caves, 1994) recommend that economic evaluation of DSM programs be institutionalized in electric-utility planning--i.e., that evaluation of DSM programs include price effects to accurately estimate the programs' effects on both participants and non-participants. By recommending that economic "surplus" be used to estimate the cost-effectiveness of DSM programs, the authors switch the emphasis in DSM-program evaluation from cost to value, from costs to net benefits, from a financial analysis to an economic one.

The financial and economic approaches can result in different conclusions about the cost-effectiveness of DSM programs. Caves, Christensen, Schoech, and Hendricks (1984), for example, compared approaches to estimating the cost-effectiveness of TOU pricing for four utilities in Illinois. They used three different methods to calculate net consumer and producer benefits. The authors concluded that there is a substantial difference in estimated program net benefits when using (1) the "correct" welfare measure of both consumer and producer benefits and (2) other approaches.

We recognize these important differences between financial and economic approaches, especially the fact that the two may result in different conclusions about the cost-effectiveness of DSM programs in real-world applications. In this study, however, we use the financial paradigm exclusively because our objective is to estimate the relative financial attractiveness of TOU pricing, technical DSM programs, and generating plants as a utility-planning practitioner--without access to data for conducting an economic evaluation--views cost-effectiveness. To the extent that the three resource options have different effects on economic measures of cost-effectiveness, the more likely that conclusions about their relative economic attractiveness would differ from the conclusions in this study. As we recommend in Section 6, an economic comparison of the three resources should be the subject of another study.

\subsection{SAFEPLAN AND COST-EFFECTIVENESS}

A number of models have been developed with varying degrees of complexity and data requirements to facilitate the IRP process. Examples include IRP-Manager developed by Electric Power Software (1993); the Multiobjective Integrated Decision Analysis System (MIDAS) developed for the Electric Power Research Institute (Temple, Barker, and Sloane, 1988); UPlan developed by the Lotus Consulting Group (1988); the Decision Impact Assessment Model (DIAMOND) developed by Oak Ridge National Laboratory (Gettings, Hirst, and Yourstone, 1991); and Scenario Analysis Framework for Expansion Planning (SafePlan) developed by Policy Planning Associates (1990).

SafePlan was selected because it calculates benefit-cost ratios for candidate 
resources, which are the most important measures of relative financial attractiveness used in this study. ${ }^{2}$ Because the model is used for developing integrated resource plans, it distingulshes between candidate resources included in a plan and those same resources being considered for inclusion in a plan.

In Figure 5.1, we show how benefit-cost ratios are calculated in SafePlan.

Figure 5.1

Calculation of Benefit-Cost Ratios in SafePlan

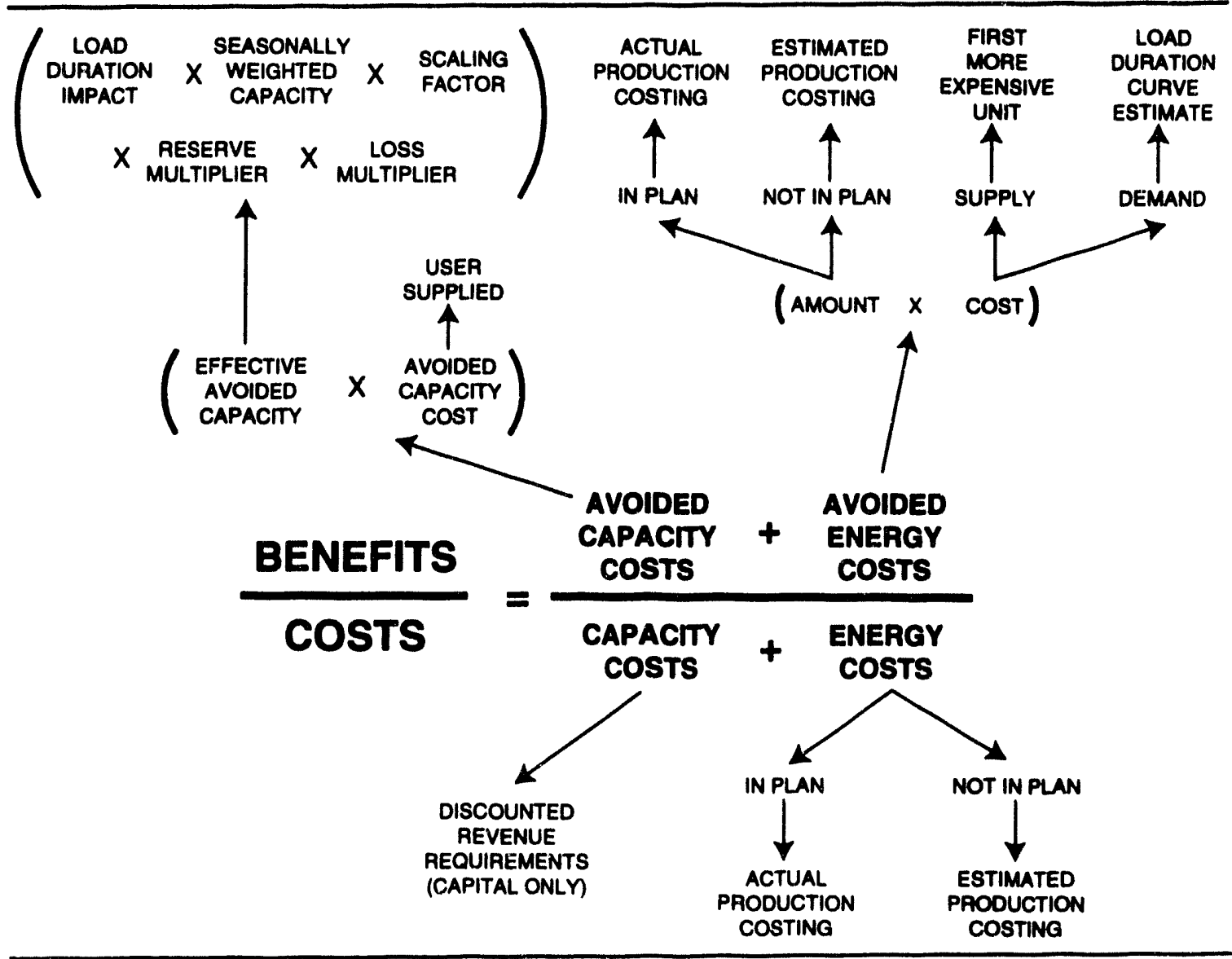

Capacity costs for candidate generating plants are calculated as the present value of the time stream of construction expenditures provided by the user for each candidate resource. The energy costs for a candidate project included in the plan are estimated by

${ }^{2}$ The features of SafePlan are contained in its documentation (Policy Planning Associates, 1990). For a concise description of its features, see Hill (1991c). 
economic dispatch in the production costing model. For resources not included in a plan, energy costs are estimated from units that were included in the dispatch. The capacity utilization factor of the next more expensive unit in the dispatch is used to determine the amount of energy assigned to the project. If a candidate resource is more expensive than the last unit, it is assigned the capacity utilization factor of the last unit. To determine energy costs, these running rates are multiplied by the variable costs of the candidate resources provided by the user.

Calculating the avoided energy and capacity costs is more complex. Avoided capacity costs are the product of a user-supplied avoided capacity value and effective avoided capacity. The latter is the product of several factors and is important in determining the capacity contribution of DSM resources. For example, because DSM resources reduce capacity requirements, they also reduce corresponding reserve requirements. Avoided energy costs are estimated as the cost of supplying energy with other resources in the plan. They are the weighted average of the costs of units that have available generation and are more expensive than the candidate resource. Each candidate resource, therefore, has a unique avoided cost. For avoided energy costs of supply resources, the "first more expensive unit" is the utilization-weighted average cost of under-utilized, more expensive units. The avoided energy costs of candidate DSM resources are estimated using their effects on the load duration curve.

\subsection{SUMMARY OF RESULTS}

\subsubsection{Low-Volume Customers}

In Table 5.1, we present simulation results for low-volume customers, comparing generating plants, technical DSM programs, and TOU pricing. The generating plants were defined in Table 4.2, the technical DSM programs in Table 4.1 and Figures 4.1 and 4.2, and the TOU-pricing resource in Tables 3.3 and 3.4 and Figure 3.1.

The results in Table 5.1 are normalized to the benefit-cost ratios of the combustion turbine generating plant for each of the three peak periods. The actual benefit-cost ratios for the combustion turbine are shown in small print below their normalized values. Using this normalization procedure, the benefit-cost ratios for every resource option under the one-hour peak scenarios were divided by 1.14 . Similarly, for three- and five-hour peaks, the benefit-cost ratios were divided by 1.09 and 1.08 , respectively.

Looking across the peak-hour scenarios in Table 5.1, the coal and combined cycle plants become more financially attractive relative to the combustion turbine as the number of peak hours increases (i.e., their normalized benefit-cost ratios increase). The reason is the relatively higher fuel intensity of the combustion turbine. As the number of hours in the peak increases, the net benefits of generating electricity with the combustion turbine decrease relative to the two other plant types.

Running technical DSM programs becomes more financially attractive as the number of peak hours increases. Because peak-period hours are more costly to serve 
than offpeak hours, the higher the number of kWh served by DSM programs during peak hours, the higher the benefits (i.e., avoided costs) of running the programs. Hence, the more financially attractive the DSM programs become. Obviously, for any given number of peak hours, higher costs of conserved energy (CCE) result in less financially attractive DSM programs.

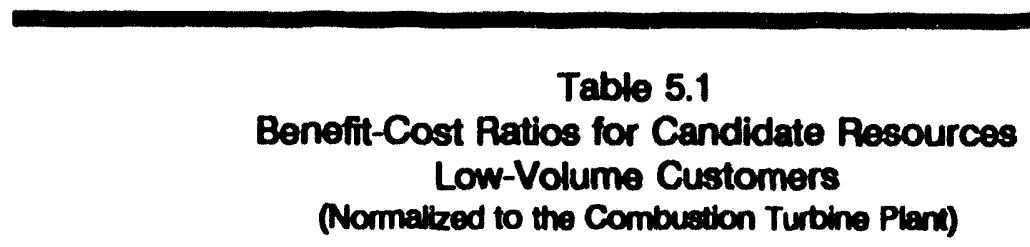

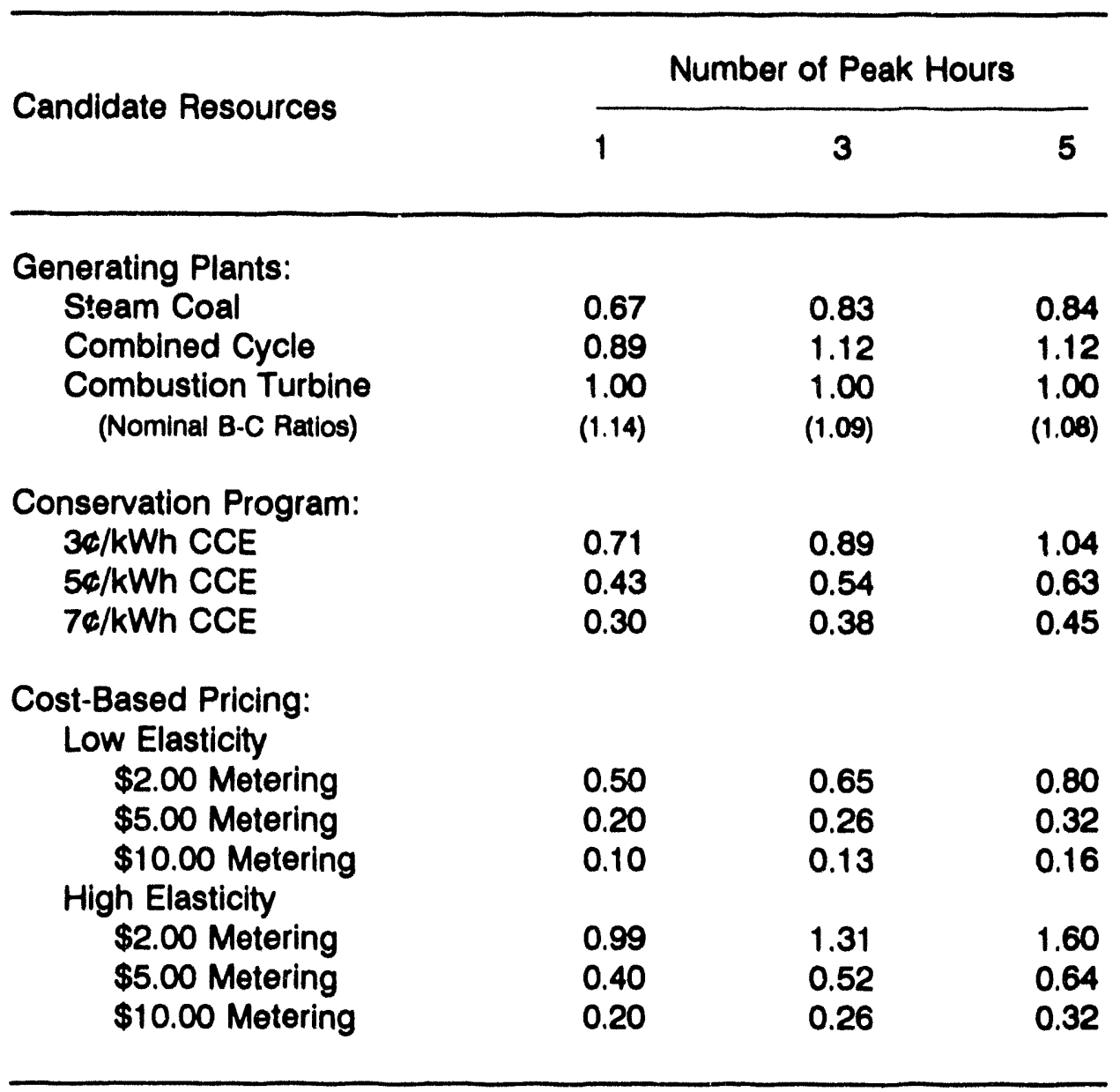

A 'low-volume customer' consumes $10,000 \mathrm{kWh}$ of electricity per year. Given 4,378.2 Gwh of consumption in the base year, there are 437,825 low-volume customers.

CCE - Cost of Conserved Energy 
For similar reasons, more peak hours for the TOU pricing resource results in larger normalized benefit-cost ratios. Comparing financial attractiveness for different elasticities, assumptions made about the responsiveness of electricity demand to changes in the peak-to-offpeak price ratio is a very important determinant of the cost-effectiveness of the pricing resource. Because we doubled the responsiveness of the pricing resource in the high-elasticity case in comparison with the low-elasticlty one, the normalized benefit-cost ratios double from the low- to high-elasticity cases shown in Table 5.1. Looking down columns for a given elasticity, incremental metering costs are also important determinants of cost-effectiveness. For example, in the three-hour peak case with high elasticity, the normalized benefit-cost ratio declines from 1.31 to 0.26 as metering costs increase from $\$ 2.00$ to $\$ 10.00$ per customer per month. The realtionship between cost-effectiveness and metering costs is shown in Figure 5.2.

Figure 5.2

Cost-Effectiveness of the TOU Pricing Program

Various Motering Costs

Low-Volume Customers

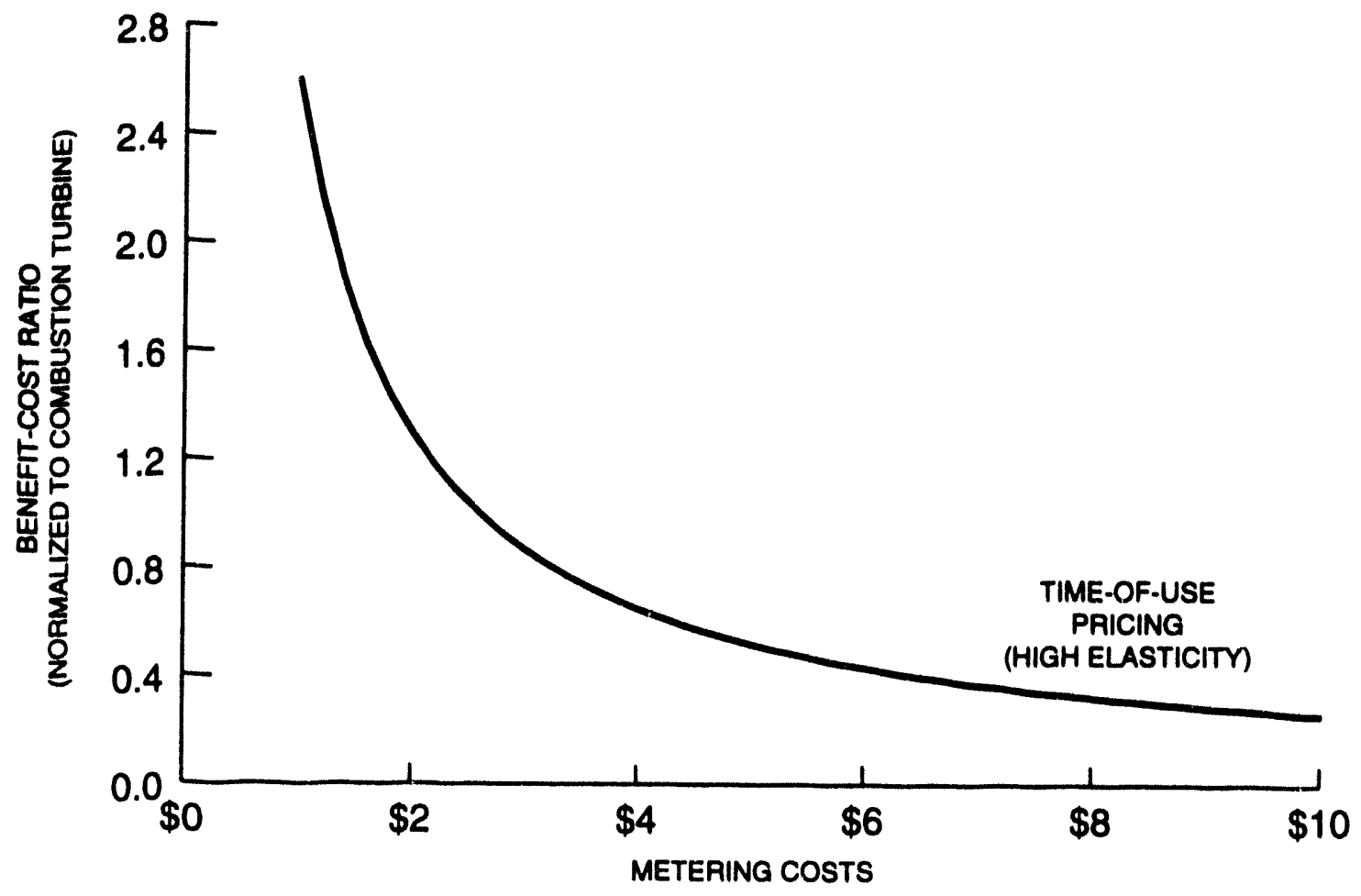

Comparing resource options, the results in Table 5.1 suggest that TOU pricing for low-volume customers is only relatively more cost-effective than a combined cycle plant 
under assumptions of three- and five-hour peaks and favorable assumptions about customer responses to cost-based rates (l.e., high price elasticity) and metering costs (\$2.00/month/customer additional metering costs).

However, the results also indicate that TOU pricing compares favorably with the conservation program under less favorable assumptions about metering costs and price responsiveness. For example, given a $7 \mathrm{c} / \mathrm{kWh}$ CCE for conservation, TOU pricing is more financially attractive than the conservation program under assumptions of low price responsiveness and $\$ 2.00$ metering costs for all lengths of the peak period. Given $5 \% / \mathrm{kWh}$ CCE, cost-based pricing for the low-elasticity case is more attractive than the conservation program only under the assumption of $\$ 2.00$ metering costs.

In the high-elasticity case, TOU pricing is more attractive than 7c/kWh CCE under both $\$ 2.00$ and $\$ 5.00$ metering-cost assumptions. Given a $5 \% / \mathrm{kWh}$ CCE for conservation, TOU pricing is more financially attractive assuming $\$ 2.00$ metering costs under both high and low elasticity assumptions. It is also more attractive assuming $\$ 5.00$ metering costs under the high-elasticity assumption. Given $3 c / \mathrm{kWh}$ CCE, cost-based pricing is more financially attractive than the conservation program only under the most favorable assumptions about the pricing resource: high price responsiveness and low metering costs.

As indicated in Table 4.1, the results for technical DSM programs are based on a conservation load factor (CLF) of 0.6. In Figure 5.2, we show the effects of varying the CLF on the financial attractiveness of the conservation program, assuming $36 / k W h$ CCE and a 3-hour peak period. The relationship in Figure 5.2 shows that the costeffectiveness of the conservation program varies with the CLF. The higher the CLF, the more attractive the program becomes. At very high levels, the program becomes more attractive than a combustion turbine. Assuming the $C L F=0.8$, the normalized benefit-cost ratio is 1.02 . However, assuming the $C L F=0.2$, the normalized benefit-cost ratio is 0.63 .

Changes in other assumptions also can change conclusions about the costeffectiveness of resources. In Table 5.2, we compare the three-hour peak reference case with three other scenarios: (1) system load factor changes from 0.6 to 0.5 ; (2) no assumed real increase in fuel prices; and (3) combustion turbines are the only existing generating units in the base year. For ease of interpretation, the benefit-cost ratios in Table 5.2 are not normalized to the combustion turbine.

Lowering the system load factor from 0.6 to 0.5 makes the combustion turbine generating plant significantly more attractive than the other two plants. The reason is that in lowering the system load factor, we reduced the intermediate or shoulder load, keeping the peak and offpeak loads at their base level. With the new load curve now almost bimodal, the lower capital costs of the combustion turbine for peaking purposes makes it relatively more attractive. The lower system load factor increases the attractiveness of both the conservation program under all assumed CCE and TOU pricing under all metering-cost assumptions and price elasticities. The nearly bi-modal load curve is the reason. The conservation program and TOU pricing have significant effects on peak load (see Figure 3.1 and Figure 4.2). 
Figure 5.3

Coet-Eflectiveneses of the Conservation Program

Verious Conservation Loed Factors

Low-Volume Cuetomers

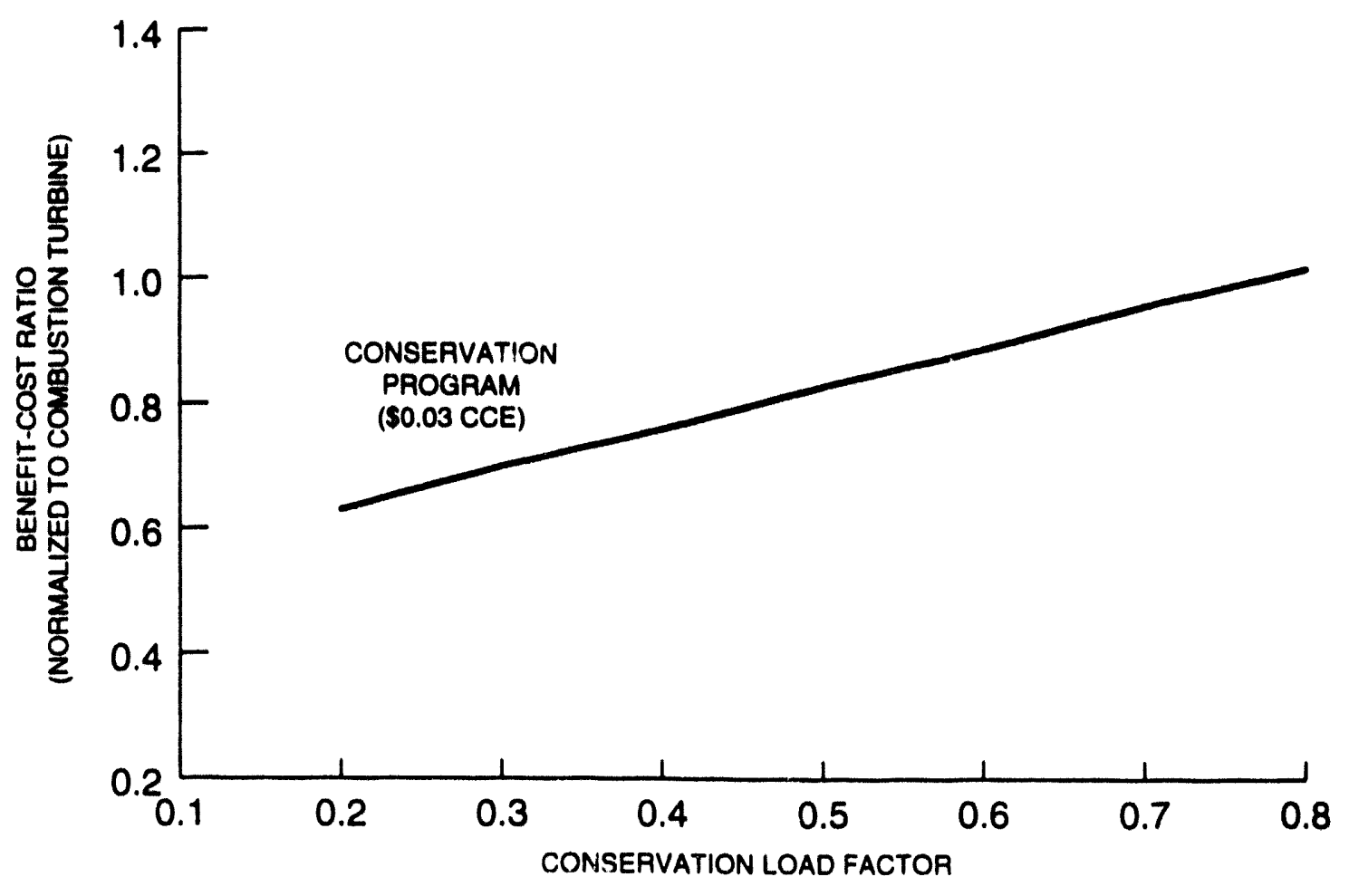

Because fuel prices are an important part of the avoided energy costs of candidate resources, assuming no fuel-price growth reduces the financial attractiveness of the conservation program and TOU pricing in comparison with the base case. However, the effect is not great--especially for the TOU-pricing program.

Assuming that the base-year generating mix consists entirely of combustion turbines changes the relative attractiveness of the conservation program and TOU-pricing resource: the conservation program becomes more financially attractive, while the benefitcost ratios for TOU pricing generally deteriorate in comparison with the base case. The reason is an artifact of the way in which the two resources were defined. The conservation program lowers load at all points on the load duration curve (Figure 4.2). The TOU-pricing resource lowers load at the peak, but increases it during base periods (Figure 3.1). Because generating electricity during base periods using combustion turbines is more costly than generation from the average utility defined in the base case, 
TOU pricing is relatively more costly in the combustion turbine scenario than in the base case.

\begin{tabular}{|c|c|c|c|c|}
\hline \multicolumn{5}{|c|}{$\begin{array}{c}\text { Table } 5.2 \\
\text { Benefit-Cost Ratios for Candidate Resources } \\
\text { Sensitivities to Input Assumptions } \\
\text { Low-Volume Customers }\end{array}$} \\
\hline Candidate Resources & $\begin{array}{c}\text { Reference } \\
\text { Case" }\end{array}$ & $\begin{array}{l}\text { System } \\
L F=0.5^{b}\end{array}$ & $\begin{array}{c}\text { No Fuel } \\
\text { Price Increase }\end{array}$ & $\begin{array}{l}\text { All CT } \\
\text { System }^{d}\end{array}$ \\
\hline \multicolumn{5}{|l|}{ Generating Plants: } \\
\hline $\begin{array}{l}\text { Steam Coal } \\
\text { Combined Cycle } \\
\text { Combustion Turbine }\end{array}$ & $\begin{array}{l}0.91 \\
1.22 \\
1.09\end{array}$ & $\begin{array}{l}0.78 \\
0.92 \\
1.06\end{array}$ & $\begin{array}{l}0.78 \\
1.22 \\
0.99\end{array}$ & $\begin{array}{l}1.09 \\
1.59 \\
1.16\end{array}$ \\
\hline $\begin{array}{l}\text { Conservation Program: } \\
\text { 36/kWh CCE } \\
\text { 56/kWh CCE } \\
\text { 7ø/kWh CCE }\end{array}$ & $\begin{array}{l}0.97 \\
0.58 \\
0.42\end{array}$ & $\begin{array}{l}1.14 \\
0.68 \\
0.49\end{array}$ & $\begin{array}{l}0.81 \\
0.49 \\
0.35\end{array}$ & $\begin{array}{l}1.30 \\
0.78 \\
0.55\end{array}$ \\
\hline \multicolumn{5}{|l|}{$\begin{array}{l}\text { Cost-Based Pricing } \\
\text { Low Elasticity }\end{array}$} \\
\hline $\begin{array}{l}\$ 2.00 \text { Metering } \\
\$ 5.00 \text { Metering } \\
\$ 10.00 \text { Metering } \\
\text { High Elasticity }\end{array}$ & $\begin{array}{l}0.71 \\
0.28 \\
0.14\end{array}$ & $\begin{array}{l}0.78 \\
0.31 \\
0.16\end{array}$ & $\begin{array}{l}0.67 \\
0.27 \\
0.13\end{array}$ & $\begin{array}{l}0.61 \\
0.25 \\
0.12\end{array}$ \\
\hline $\begin{array}{l}\$ 2.00 \text { Metering } \\
\$ 5.00 \text { Metering } \\
\$ 10.00 \text { Metering }\end{array}$ & $\begin{array}{l}1.43 \\
0.57 \\
0.28\end{array}$ & $\begin{array}{l}1.56 \\
0.63 \\
0.31\end{array}$ & $\begin{array}{l}1.33 \\
0.53 \\
0.27\end{array}$ & $\begin{array}{l}1.23 \\
0.49 \\
0.25\end{array}$ \\
\hline
\end{tabular}

In the reference case, we assume a three-hour peak, a 0.60 system load factor, fuel price growth at the rate forecasted by the Energy Information Administration, and a generating mix reflecting the U.S. average.

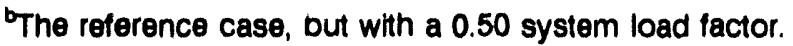

'The reference case, but with no fuel-price growth.

The reference case, but with an existing combustion turbine generating mix.

In Tables 5.1 and 5.2, we use one measure of the relative attractiveness of resource options: their benefit-cost ratios. This measure, however, provides no indication 
of the relative size of the resources. In Table 5.3, we provide the net present value of revenue requirements for each of the candidate resources under base-case assumptions under a three-hour peak.

\begin{tabular}{|c|c|}
\hline \multicolumn{2}{|c|}{$\begin{array}{c}\text { Table } 5.3 \\
\text { Revenue Requirements for Candidate Resources } \\
\text { Low-Volume Customers } \\
\text { (n } 1993 \$ 000)\end{array}$} \\
\hline Candidate Resources & Amount \\
\hline $\begin{array}{l}\text { Generating Plants: } \\
\text { Steam Coal } \\
\text { Combined Cycle } \\
\text { Combustion Turbine }\end{array}$ & $\begin{array}{r}521,725 \\
76,520 \\
59,224\end{array}$ \\
\hline $\begin{array}{l}\text { Conservation Program: } \\
\text { 3๘/kWh CCE } \\
5 \% / k W h ~ C C E \\
\text { 7๕/kWh CCE }\end{array}$ & $\begin{array}{l}33,944 \\
56,580 \\
79,198\end{array}$ \\
\hline $\begin{array}{l}\text { Cost-Based Pricing } \\
\text { Low Elasticity } \\
\$ 2.00 \text { Metering } \\
\$ 5.00 \text { Metering } \\
\text { \$10.00 Metering } \\
\text { High Elasticity } \\
\$ 2.00 \text { Metering } \\
\$ 5.00 \text { Metering } \\
\$ 10.00 \text { Metering }\end{array}$ & $\begin{array}{r}102,338 \\
255,845 \\
511,680 \\
102,338 \\
255,845 \\
511,680\end{array}$ \\
\hline
\end{tabular}

The data and their interpretation in Tables 5.1 through 5.3 provide a range of possibilities for the relative attractiveness of resource options. In real-world applications, of course, attractiveness of resources depends on actual characteristics of individual utilities. Three observations are relevant.

First, the 0.6 CLF assumed for conservation programs in the reference case is probably too high for most programs in real-world applications. Therefore, the financial attractiveness of these programs is probably less than what we have shown in Tables 5.1 and 5.2. The CCE for new conservation programs is even more utility-specific and depends both on the aggressiveness of that utility in running these programs in the past 
(i.e., cream-skimming) and the efficiency of the utility (or energy service company) in running the program.

Second, the 10,000-kWh average consumption level assumed for low-volume customers suggests that these customers are at the lower end of the elasticity range used in the simulations. The higher the average consumption, the greater the responsiveness of low-volume customers to cost-based pricing. On the other hand, as the discussion in Section 3 suggests, the incremental metering costs for low-volume customers are probably closer to $\$ 2.00$ per customer per month, rather than $\$ 10.00$. Therefore, all of the results for $\$ 2.00$ metering are probably more representative for realworld utilities.

Third, the longer the system peak for a utility, the more financially attractive conservation programs and cost-based pricing become. However, the length of peak and system load factor interact.

\subsubsection{Medium- and High-Volume Customers}

In Table 5.4, we compare the cost-effectiveness of DSM options for mediumvolume customers. For these customers, we also include a load management program, assuming $\$ 25, \$ 75$, and $\$ 125$ cost of conserved capacity (CCC). ${ }^{3}$ All of the relationships between cost-effectiveness, length of peak period, system and conservation load factors, and metering costs are the same for medium-volume customers as for low-volume ones. Therefore, we will not repeat them here. However, two additional comments are appropriate.

First, the data indicate that the load management program is generally more costeffective than the conservation program. At the extreme, the load management program assuming $\$ 125 \mathrm{CCC}$ is competitive with the conservation program assuning $3 \mathrm{c} / \mathrm{kWh} \mathrm{CCE}$. For example, assuming a five-hour peak, the normalized benefit-cost ratio for the $\$ 125$ load management program is 1.06 in comparison with the 1.04 ratio for the $36 / \mathrm{kWh}$ conservation program.

Second, like conservation programs, TOU pricing is only financially attractive under the most favorable assumptions for medium-volume customers. That is, TOU pricing is only more financially attractive than a combustion turbine (i.e., normalized benefit-cost ratio greater than 1.00) assuming high elasticity, $\$ 2.00$ metering costs, and a five-hour peak. The reason is the low response of this class of customers to TOU rates (Section 3.2). The conservation program is more attractive than a combustion turbine

\footnotetext{
${ }^{3} \mathrm{~A}$ load management program was devised for medium-volume customers because they most closely reflect the type of customer for which this program is implemented in real-world applications. As the note at the bottom of Table 5.4 indicates, the medium-volume customer consumes $60,000 \mathrm{kWh}$ of electricity per year, closely approximating the amount of average U.S. commercial consumption. Assuming a load factor of 0.50 , the average customer has peak consumption of $13.7 \mathrm{~kW}$. In our simulations, we assumed that the average savings per customer was 20 percent or approximately $3 \mathrm{~kW}$.
} 
only assuming a five-hour peak with 3G/kWh CCE.

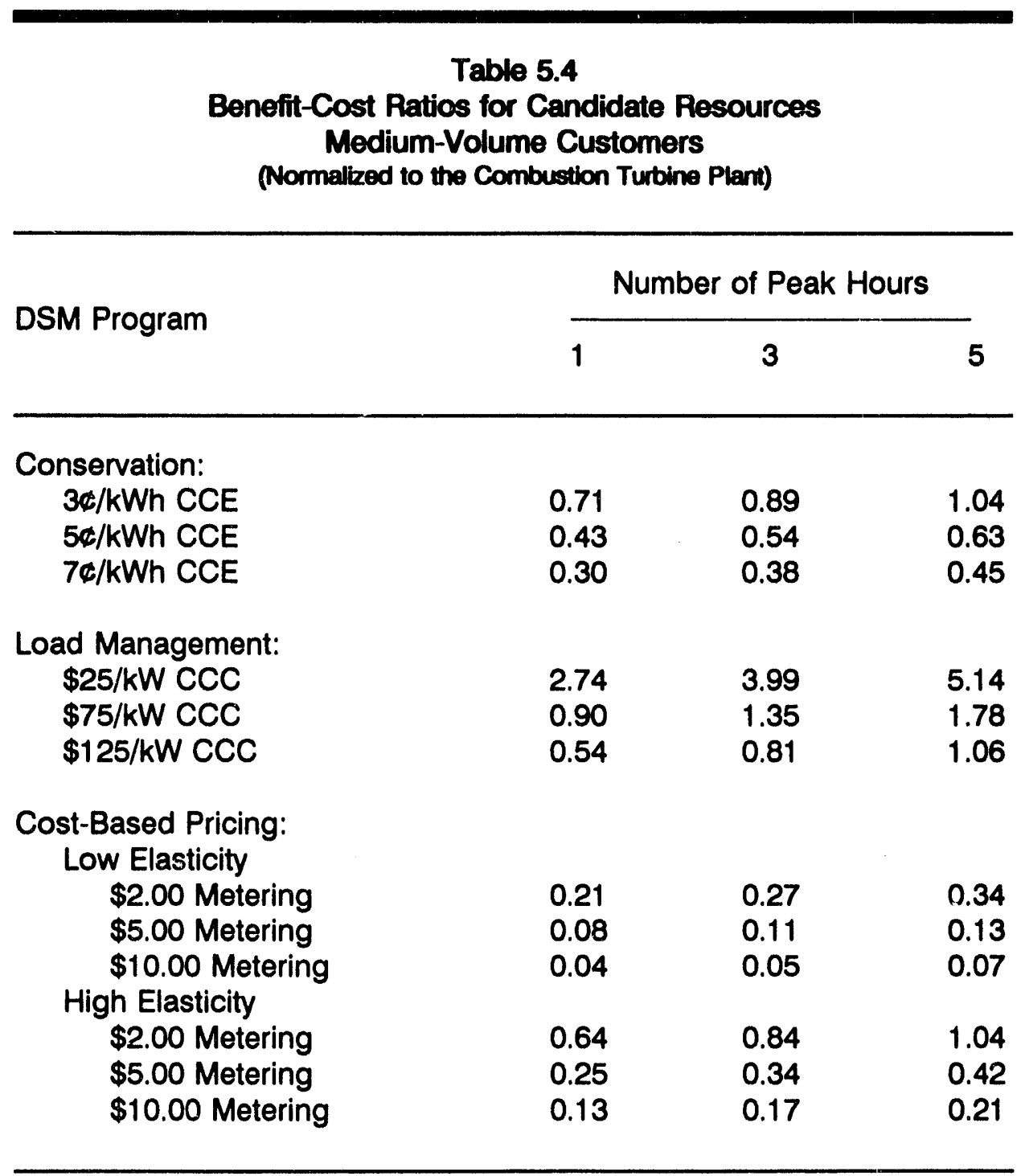

A 'medium-volume customer' consumes $60,000 \mathrm{kWh}$ of electricity per year. Given $4,378.2$ Gwh of consumption in the base year, there are 72,970 medium-volume customers.

CCE - Cost of Conserved Energy

CCC - Cost of Conserved Capacity

In real-world applications, the data in Table 5.4 indicate that the load management program is the most attractive program for the commercial sector. As indicated in Table 4.1 , the load management program results in $132 \mathrm{MW}$ of savings. The $\$ 5.00$ metering costs for commercial customers most closely approximate the incremental costs for this 
class (Table 3.4). However, from Table 5.4, the price elasticity and/or the length of the peak period would have to increase substantially for TOU pricing to be more financially attractive than constructing a combustion turbine plant (i.e., normalized benefit-cost ratio greater than 1.0).

The benefit-cost results for TOU pricing in the medium-volume customer class are reversed for the high-volume class. We present the results in Table 5.5. As the note to the table indicates, the high-volume customer consumes $1,870 \mathrm{GWh}$ per year, closely approximating the average U.S. industrial customer. In this case, cost-based pricing is the most attractive DSM option. Under the most unfavorable assumptions (low elasticity; $\$ 10$ metering costs), pricing is more attractive than conservation programs assuming the most favorable conditions (3G/kWh CCE) for all peak periods.

As discussed in Section 3.2, the high-volume response to cost-based pricing depends crucially on the mix of manufacturing processes that a utility serves. For many utilities in real-world applications, the results for TOU pricing shown in Table $\mathbf{5 . 5}$ will underestimate the response in practice. As discussed in Section 3.3, we made no distinction between short- and long-run elasticities for the pricing resources. We simply assumed a reasonable range of elasticities and applied them to each year's consumption. However, there is evidence that processes and electricity usage change over time in response to cost-based pricing in the industrial sector. To the extent that this occurs, the results in Table 5.5 underestimate TOU pricing's effect.

\subsubsection{A Closer Look at Pricing}

In Table 5.6, we compare the financial attractiveness of the pricing resource for the three customer classes. Cost-based pricing is significantly more cost-effective for high-volume customers than for low- or medium-volume ones, even though the price responsiveness for high-volume customers is much less than for low-volume customers. The reason is that the total and relative costs of metering are much lower for high-volume customers (2,340 v. 437,825 customers) and average load is much greater. In Figure 5.4, using the data in Table 5.6, we show the change in cost-effectiveness for each of the three customer classes under different assumptions about the length of peak periods. The metering costs for each of the three customer classes are the best guesses of what they would be in practice for each of the three customer classes: $\$ 2.00$ for low-volume, $\$ 5.00$ for medium-volume, and $\$ 10.00$ for high-volume customers. 
Table 5.5

Benefit-Cost Ratios for Candidate Resources

High-Volume Customers

(Normalized to the Combustion Turbine Plant)

\begin{tabular}{|c|c|c|c|}
\hline \multirow{2}{*}{ DSM Program } & \multicolumn{3}{|c|}{ Number of Peak Hours } \\
\hline & 1 & 3 & 5 \\
\hline \multicolumn{4}{|l|}{ Conservation: } \\
\hline 3\%/kW/h CCE & 0.71 & 0.89 & 1.04 \\
\hline 5\%/kWh CCE & 0.43 & 0.54 & 0.63 \\
\hline 7q/kWh CCE & 0.30 & 0.38 & 0.45 \\
\hline \multicolumn{4}{|l|}{ Load Management: } \\
\hline$\$ 25 / \mathrm{kW}$ CCC & 2.74 & 3.99 & 5.14 \\
\hline$\$ 75 / \mathrm{kW}$ CCC & 0.90 & 1.35 & 1.78 \\
\hline$\$ 125 / \mathrm{kW}$ CCC & 0.54 & 0.81 & 1.06 \\
\hline \multicolumn{4}{|l|}{$\begin{array}{c}\text { Cost-Based Pricing: } \\
\text { Low Elasticity }\end{array}$} \\
\hline$\$ 2.00$ Metering & 5.48 & 7.06 & 8.42 \\
\hline$\$ 5.00$ Metering & 2.14 & 2.87 & 3.43 \\
\hline$\$ 10.00$ Metering & 1.07 & 1.41 & 1.71 \\
\hline \multicolumn{4}{|l|}{ High Elasticity } \\
\hline$\$ 2.00$ Metering & 29.24 & 45.87 & 46.30 \\
\hline$\$ 5.00$ Metering & 12.53 & 18.35 & 23.15 \\
\hline$\$ 10.00$ Metering & 6.75 & 9.17 & 11.57 \\
\hline
\end{tabular}

A 'high-volume customer' consumes $1,870 \mathrm{MWh}$ of electricty per year. Given 4,378.2 Gwh of consumption in the base year, there are 2,340 high-volume customers.

CCE - Cost of Conserved Energy

CCC - Cost of Conserved Capacity 
Table 5.6

Benefit Cost Ratios for TOU Pricing

Low- vs. Medium- vs. High-Volume Customers

(Normalized to the Combustion Turbine Plant)

Type of Customer

Number of Peak Hours

\begin{tabular}{lll}
\hline 1 & 5
\end{tabular}

Low-Volume Customers:

Low Elasticity

$\$ 2.00$ Metering

$\$ 5.00$ Metering

0.50

0.65

0.80

$\$ 10.00$ Metering

0.20

0.26

0.32

High Elasticity

$\$ 2.00$ Metering

$\$ 5.00$ Metering

0.10

0.13

0.16

$\$ 10.00$ Metering

$\begin{array}{lll}0.99 & 1.31 & 1.60 \\ 0.40 & 0.52 & 0.64 \\ 0.20 & 0.26 & 0.32\end{array}$

Medium-Volume Customers:

Low Elasticity

$\$ 2.00$ Metering

$\$ 5.00$ Metering

$\$ 10.00$ Metering

0.21

0.27

0.34

0.08

0.11

0.13

High Elasticity

$\$ 2.00$ Metering

0.04

0.05

0.07

$\$ 5.00$ Metering

0.64

0.84

1.04

0.25

0.34

0.42

$\$ 10.00$ Metering

0.13

0.17

0.21

High-Volume Customers:

Low Elasticity

$\$ 2.00$ Metering

$\$ 5.00$ Metering

$\$ 10.00$ Metering

High Elasticity

$\$ 2.00$ Metering

$\$ 5.00$ Metering

$\$ 10.00$ Metering

5.48

2.14

1.07

29.24

12.53

6.75

18.35

11.57 
Figure 5.4

Benefit-Cost Ratios for TOU Pricing

Varying PeakPeriod Lengths

Three Customer Classes

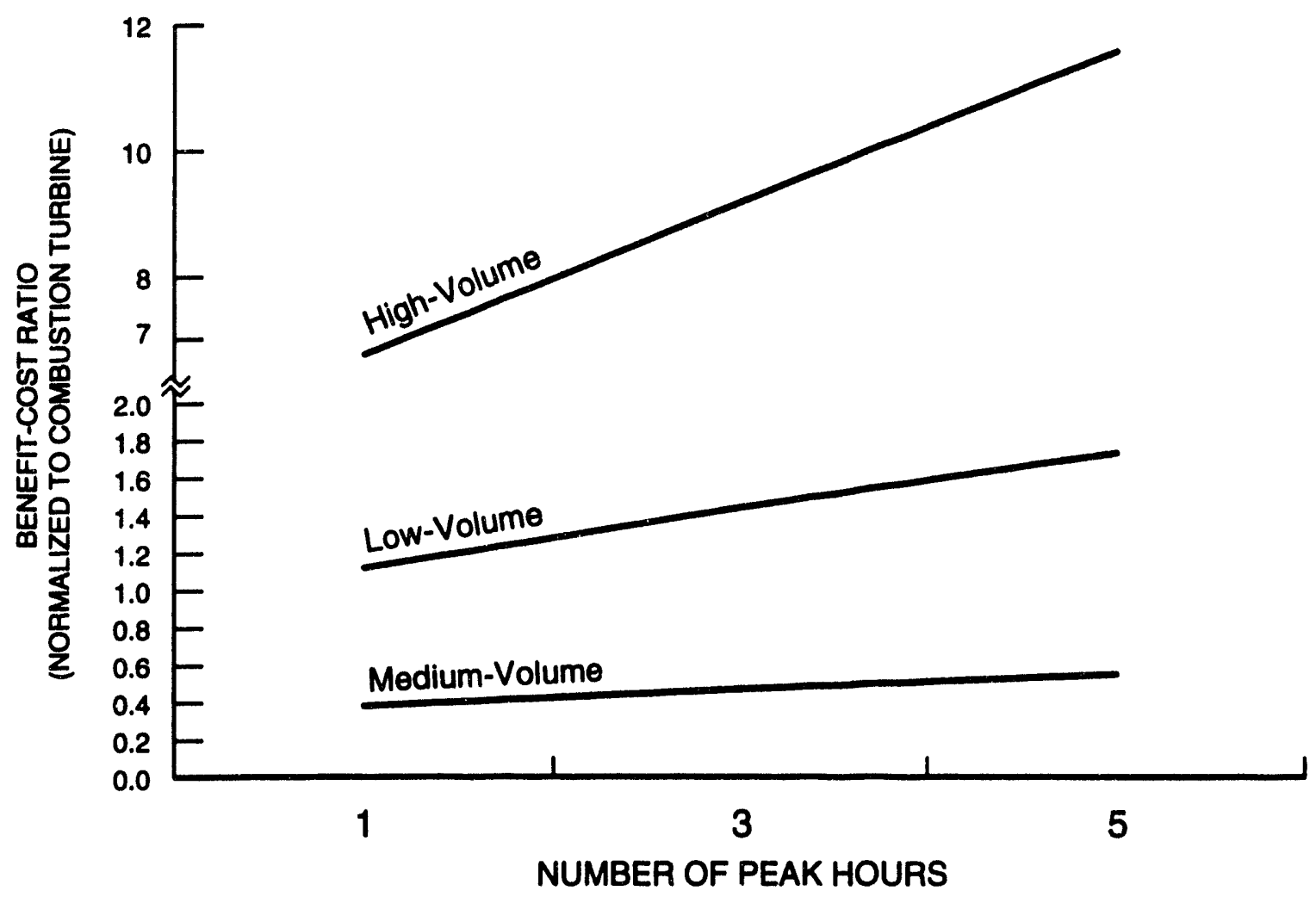

5.16 


\section{SYNTHESIS AND RECOMMENDATIONS}

\subsection{THE STUDY IN CONTEXT}

This study comparing TOU pricing with other electric-utility resource options answered some important questions about conditions under which cost-based pricing should be financially attractive to an electric utility, but the study also raised other important questions for consideration both by utilities and regulators. As such, the study serves as a foundation for further investigation into pricing-related issues relating both to an electric utility's planning process and public policy.

An important consideration in reviewing the results of this study is the framework under which resource options were evaluated. Because our objective was to indicate conditions under which TOU pricing is financially attractive, we took a practitioner's view in estimating the relative cost-effectiveness of resource options. That is, we placed ourselves in the chair of the utility planner, looking for the least-cost mix of resources to satisfy the future load requirements of a hypothetical utility. Using this paradigm, we concluded that TOU pricing compares favorably with generating plants and technical DSM programs, depending on conditions under which the utility operates. However, we also observed that this least-cost, financial framework may underestimate the costeffectiveness of TOU pricing viewed from an economic perspective. This issue is worth investigating in future work.

We also took a limited view of the pricing resource itself, confining our attention to the short-run, direct effects of TOU pricing. By focusing exclusively on TOU pricing in the short run, we probably underestimated the total amount of the pricing resource available to most electric utilities. Setting electricity rates to reflect the long-run marginal cost of electricity supply is another potential source of electric-utility resources that may compete more favorably with generating units than TOU pricing does, and with conservation programs than load management programs. By focusing exclusively on pricing's direct effects, we did not capture the amount of price-induced energy conservation that may exist from (1) TOU pricing during peak hours and (2) higher overall levels of rates that reflect long-run marginal supply costs.

Despite the myopic view, the results of the study have important implications for the relative financial attractiveness of resources in electric-utility planning. We turn now to these implications.

\subsection{RELEVANCE OF THE RESULTS FOR ELECTRIC-UTIUTY PLANNING}

The simulation results on TOU pricing reported in this study, of course, are relevant for only a subset of utilities in the U.S. electric power industry. Many electric utilities in their planning processes have already conducted analyses similar to this one and have acquired the most cost-effective resources. For those utilities that have not considered TOU pricing in their planning processes, however, this study indicates that they may be omitting a potentially attractive resource from consideration. And although not considered formally in this study, utilities that have not reflected the long-run supply 
cost in their rates may also be excluding an important resource from consideration in their planning processes.

Stating the obvious, the absolute and relative cost-effectiveness (as measured by benefit-cost ratios) of any behavioral or technical DSM program depends on characteristics of the utility and its customer classes. A determining factor for DSM options is the length of the peak period. The more hours in the peak, the more financially attractive TOU pricing and technical DSM programs become. This conclusion is robust under different assumptions about the hypothetical utility and values defining the parameters of its candidate resources.

The financial attractiveness of TOU pricing is customer class-specific. For highvolume customers reflecting the average consumption of U.S. industrial customers, metering costs are not as determining for cost-effectiveness as they are for other customer classes. The degree of price-responsiveness depends critically on the types of industries served by the utility. Process industries generally do not respond as much as mechanical industries--at least in the short run. However, the simulation results in this study show that TOU pricing is cost-effective (i.e., benefit-cost ratio exceeding 1.0) and more financially attractive than other resource options under assumptions of very low own-price elasticities characteristic of serving process industries.

For low-volume customers reflecting the average U.S. residential customer, priceresponsiveness and, hence, cost-effectiveness of TOU pricing depends critically on the types of durables used by these customers and, hence, the average amount of electricity consumption. Under conditions reflecting the circumstances of many electric utilities, TOU pricing is the most financially attractive resource available as measured by its benefit-cost ratio. For example, consider a utility with (1) incremental TOU-pricing metering costs of $\$ 2.00$ per customer per month, (2) a peak period lasting five hours, and (3) and low-volume customers consuming $12,000 \mathrm{kWh}$ annually. The benfit-cost ratio normalized to a combustion turbine in this circumstance is simulated to be 1.60 , significantly higher than the normalized benefit-cost ratio of the most attractive generating plant (1.12 of the combined cycle plant) and the conservation program assuming the most favorable conditions (1.04 with $36 / \mathrm{kWh}$ cost of conserved energy). And, the longer the utility's peak beyond five hours, the more attractive TOU pricing becomes.

Besides the cost of conserved energy, the most important factor determining the cost-effectiveness of conservation programs is the conservation load factor (CLF). The higher the CLF, the more financially attractive the program becomes. For load management programs, the cost of conserved capacity is obviously important in determining cost-effectiveness. Given that cost, however, the length of the system's peak period is a crucial factor. The lengthier the peak period, the more attractive the program becomes.

Of course, degrees of relative financial attractiveness alone do not determine which resources--or mix of resources--will be selected by a given utility. These financial results are indicative of what a utility should consider under a range of conditions. In realworld settings, financial considerations in decisionmaking on resource selection are 
supplemented by economic and rellability considerations.

Finally, the simulation results reported in this study do not imply what mix of resources are optimal for a utility's financial position as measured by its income statement, balance sheet, and funds flow. That requires separate inquiry. Also, the discussion of TOU pricing abtracts from potential implementation problems that an electric utility may confront in moving to cost-based rates. This is especially true if long-run supply costs are included as part of the TOU tariff and/or some classes of service have been subsidizing others for extended periods of time. In this case, the process of implementing cost-based pricing may be a more formidable task than the process of calculating cost-based rates and comparing them with other resources.

\subsection{A CLOSER LOOK AT QUESTIONS RAISED IN THE STUDY}

In the previous two subsections, seven issues were raised about the role of costbased electricity pricing and electric utilities. In the remainder of this section, we transform these issues into seven questions and provide explanations.

1. Other than the potential efficiency gains and energy savings to be realized from TOU pricing, are there other important "pricing resources" as yet unexploited in the U.S. electric power industry?

We define the "pricing resource" in this study on the basis of differences in shortrun operating costs at different times of the day. Besides these short-run, peaking resources, pricing can be used as a source of longer-run, base-load resources by setting the civerall level of electricity prices to reflect the long-run marginal capacity costs. The question becomes: How does this base-load resource compare financially (and economically) with technical DSM programs and generating plants?

2. To what extent is cost-based pricing being utilized in the U.S. electric power sector and what is the amount still unexploited?

Surveys of the U.S. electric utility industry indicate that not all utilities have implemented TOU pricing, suggesting that there is still an unexploited pricing resource. Moreover, although the evidence is not as concrete, indications are that electric utilities are not pricing at long-run marginal cost. This suggests (1) that there could be still a larger untapped resource and/or (2) the resource could vary geographically because of the large presence of publicly owned utilities in certain parts of the country $(\theta .9$., Northwest, Southeast).

An answer to this question is important from national and state public policy standpoints. If cost-effective pricing resources are nearly exhcusted at national or state levels, public policy should be directed toward increasing the turnover of the stock of inefficient electricity-using durables (e.g., utility-run technical DSM programs). If the opposite is true, however, public policy should be focused on implementing cost-based pricing. 
3. What is the effect of using cost-based pricing on a utility's financial position in comparison with running technical DSM programs and/or bullding generating units?

Holding electricity pricing as a DSM strategy aside for the moment, an important issue raised by critics of electric utilities running DSM programs is the effect these programs have on the financial viability of electric utlities. Does satisfying customer load requirements by running DSM programs result in a less financially viable utility than bullding power plants to satisty that load? Many contend that it does.' A question raised by this study then is: Are the financial effects of implementing cost-based electricity pricing less harmful to a utility's financial position than running technical DSM programs and building power plants?

The answer to this question may be more important for electric utilities that have not been historically aggressive in running technical DSM programs. For example, many municipally owned utilities are just beginning an integrated resource planning process. If cost-based pricing is shown to be more neutral on a utility's financial position (as measured in the income statement, balance sheet, and funds flow) than technical DSM programs, management of the utility may be better-advised to pursue cost-based pricing as a DSM strategy--at least at the outset.

4. What is the relative economic attractiveness of cost-based pricing, technical DSM programs, and generating plants in comparison with their financial attractiveness considered in this study?

In evaluating these three resource options, we considered only the financial benefits and costs of the programs. It is very likely that their relative attractiveness would change if economic effects were considered also. This is especially true of the relative attractiveness of cost-based pricing.

\section{How much technical energy conservation will properly priced electricity induce?}

This is an important question when placed in the context of the seventh question dealing with implementation of cost-based pricing. If the potential amount of electricity conservation induced by cost-based pricing is large, then the impetus for electricity price reform should be that much stronger. If the amount is small, it should then be given lower priority for many utilities because of problems that implementing cost-based pricing may pose in many areas of the country.

\section{utility industry?}

6. What is the role of (regulated) cost-based pricing in a more competitive electric

The issue of comparative financial viability of electric utilities under different resource portfolios (i.e., relative composition of pricing, technical DSM, and power plant resources) becomes even more pressing as the electric power industry evolves from one

\footnotetext{
'An ongoing study at ORNL is addressing that question (Hirst and Hadley, 1994).
} 
based on regulation to one based on competition. As a result of PURPA and EPACT, the U.S. electric power industry will likely evolve from a group of vertically integrated, regulated monopolies-i.e., from production through transmission to distribution--to a competitive, wholesale power production industry with regulated transmission and distribution functions. (The latter two functions have natural monopoly characteristics and competition among suppliers would likely introduce uneconomic redundancy.)

Existing utilities that are less efficient than their competitors will be relegated to 'electricity brokers': purchasing power from Independent generating companies and selling that power to ultimate users. Rather than a serles of vertically integrated companies, the industry is likely to evolve into one where there is much more specialization of function (l.e., predominant generators and transmitters (G\&Ts); transmitters and distributors (T\&Ds). Retail wheeling, in which an electricity generator uses another electric utility's transmission system to sell power to end-use customers, was originally incorporated in EPACT but deleted at the last moment. Individual states, however, are considering retail wheeling legislation for utilities in their states.

In this new competitive order, what is the role of pricing? Will and should T\&D utilities be free to set market-based prices? Will greater regulatory emphasis be placed on implementing cost-based pricing as a DSM strategy for T\&D utilities than on running technical DSM programs?

\section{What are the problems of implementing cost-based pricing?}

For some electric utilities, the conventional wisdom is that certain customer classes are subsidizing others. If this is the case, determining that prices should be raised (or lowered) for certain customer classes because of financial (i.e., cost) reasons is an issue separate from the political reality of actually raising (or lowering) them--i.e., the implementation problem. If the goal of public policy is to sei rates for all customer classes at cost-based levels and rates have been distortea (i.e., subsidized or subsidizing) for long periods of time, the key political issue may now be the process of getting rates to cost-based levels, rather than the process of calculating what correct rates should be. 


\section{REFERENCES}

Acton, Jan P. and Rolla E. Park, 1987, Response to Time-of-Day Electricity Rates by Large Business Customers: Reconcilling Conflicting Evidence, The RAND Corporation, Santa Monica, California, R-3477-NSF, August.

Baladi, S. Mostafa, Joseph A. Herriges, and Thomas J. Sweeney, 1994, "Customer Response to Voluntary Time-of-Use Electricity Rates: New Evidence from a Controlled Experiment," Proceedings: 1994 Innovative Electricity Pricing, Electric Power Research Institute, Palo Alto, California, TR-103629, February.

Boiteux, Marcel, 1949, "La Tarification des Demandes en Pointe," Revue Generale de I'Electricite, 58 (published in English in 1960 as "Peak Load Pricing," Journal of Business).

Borlick, Robert L., 1994, "When 'Least-Cost' is Wrong," Fortnightly, January 1.

Braithwait and Caves, 1994, "What Standard Practice Tests Don't Tell Us About DSMInduced Price Impacts," Proceedings: 1994 Innovative Electricity, Electric Power Research Institute, Palo Alto, California, TR-103629, February.

California Public Utilities Commission and California Energy Commission, 1987, Standard Practice Manual: Economic Analysis of Demand-Side Management Programs, December.

Caves, Douglas W., Laurits R. Christensen, and Joseph A. Herriges, 1984, "Consistency of Residential Customer Response in Time-of-Use Electricity Pricing Experiments," Journal of Econometrics, 26(1/2), September/October.

Caves, Douglas W., Laurits R. Christensen, Philip E. Schoech, and Wallace Hendricks, 1984, "A Comparison of Different Methodologies in a Case Study of Residential Time-ofUse Electricity Pricing: Cost-Benefit Analysis," Journal of Econometrics, 26(1/2), September/October.

Caves, Douglas W., Joseph A. Herriges, and Kathleen A. Kuester, 1989, "Load Shifting under Voluntary Residential Time-of-Use Rates," Energy Journal, 10(4).

CSA Energy Consultants, Inc., 1992, Suney of Innovative Rates, 1991, Three Volumes, Electric Power Research Institute, Palo Alto, California, TR-100469, April.

Edison Electric Institute, 1992, Statistical Yearbook of the Electric Utility Industry 1991, Washington, DC, October.

Electric Power Research Institute, 1989, Technical Assessment Guide: Electricity Supply, Vol. 1, Rev. 6, Palo Alto, California, December.

Electric Power Sottware, 1993, EPRI IRP-Manager User's Guide, Minneapolis, Minnesota. 
Energy Information Administration, 1993, Annual Energy Outlook: With Projections to 2010, Washington, D.C., DOE/EIA-0383(93), January.

Energy Information Administration, 1993, Assumptions for the Annual Energy Outlook 1993, Washington, DC, DOE/EIA-0527(93), January.

Faruqui, Ahmad and J. Robert Malko, 1983, "The Residential Demand for Energy by Timeof-Use: A Survey of Twelve Experiments with Peak Load Pricing," Energy, 8(10), pp. 78195.

Faruqui, Ahmad et al., 1991, Customer Response to Rate Options, Electric Power Research Institute, Palo Alto, California, CU-7131, January.

Gettings, Michael, Eric Hirst, and Evelin Yourstone, 1991, Diamond: A Model of Incremental Decision Making for Resource Acquisition by Electric Utilities, Oak Ridge National Laboratory, Oak Ridge, Tennessee, ORNL/CON-315, February.

Hirst, Eric and Stan Hadley, 1994, Effects of Resource Acquisitions on Utility Shareholders, Oak Ridge National Laboratory, Oak Ridge, Tennessee, ORNL/CON-384, Draft, March.

Hobbs, Benjamin, 1991, "The 'Most Value' Test: Economic Evaluation of Electricity Demand-Side Management Considering Customer Value," The Energy Journal, 12(2).

Hill, Lawrence J., 1988, Public Power in the U. S. Electric Utility Industry: Regulatory Issues and Comparative Financial Indicators across Ownership Types, Oak Ridge National Laboratory, Oak Ridge, Tennessee, ORNLTM-10497, January.

Hill, Lawrence J., 1990, Electricity Pricing as a Demand-Side Management Strategy: Western Lessons for Developing Countries, Oak Ridge National Laboratory, Oak Ridge, Tennessee, ORNL-6620, December.

Hill, Lawrence J., 1991a, "Large Power Users and Capacity Shortages in Developing Countries: The Role of Innovative Pricing," International Journal of Global Energy Issues, 3(2), pp. 86-96.

Hill, Lawrence J., 1991b, "Residential Time-of-Use Pricing as a Load Management Strategy: Effectiveness and Applicability," Utilities Policy, 1(4), pp. 308-318, 1991.

Hill, Lawrence J., 1991 C, Comparison of Methods to Integrate DSM and Supply Resources in Electric-Utility Planning, Oak Ridge National Laboratory, Oak Ridge, Tennessee, ORNL/CON-341, December.

Hill, Lawrence J., Eric Hirst, and Martin Schweitzer, 1991, Integrating Demand-Side Management Programs into the Resource Plans of U.S. Electric Utilities, Oak Ridge National Laboratory, Oak Ridge, Tennessee, ORNL/CON-311, January (also published by the Electric Power Research Institute, Palo Alto, California, EPRI TR-100255). 
Lotus Consulting Group, 1988, UPlan, The Electric Utility Planning System, Los Altos, California.

Mak, Jullet C. and Bruce R. Chapman, 1993, "A Survey of Current Real-Time Pricing Programs," The Electricity Journal, August/September.

Park, Rolla E. and Jan P. Acton, 1984, "Large Business Customer Response to Time-ofDay Electricity Rates," Journal of Econometrics, 26(1/2), September/October.

Policy Planning Associates, 1991, SAFEPLAN (Scenario Analysis Framework for Expansion Planning): Users' Manual, Kirkland, Washington.

Temple, Barker, and Sloane, 1988, Multiobjective Integrated Decision Anahysis System (MIDAS), Vol. 1: Model Overviow, Electric Power Research Institute, Palo Alto, California, EPRI P-5402, April.

U.S. Department of Energy, 1991/1992, Integrated Analysis Supporting the National Energy Strategy: Methodology, Assumptions, and Results, Technical Annex 2, Washington, DC. 
ORNL/CON-352

INTERNAL DISTRIBUTION

1. D. Bauer

2. L. Baxter

3. V. D. Baxter

4. L. Berry

5. D. S. Bjornstad

6. R. Braid

7. M. A. Brown

8. J. B. Cannon

9. R. S. Carlsmith

10. F. C. Chen

11. J. Christian

12. G. Courville

13. T. R. Curlee

14. P. D. Fairchild

15. W. Fulkerson

16. S. Hadley

17. L. J. Hill

18. E. Hillsman

19. E. Hirst

20. P. J. Hughes

21. J. O. Kolb

22. M. A. Kuliasha
23. R. Lee

24. P. Leiby

25. J. M. MacDonald

26. V. C. Mei

27. W. R. Mixon

28. S. Purucker

29. D. E. Reichle

30. D. T. Rizy

31. M. Schweitzer

32. R. B. Shelton

33. B. E. Tonn

34. J. Van Dyke

35. J. Vancoevering

36. J. M. Veigel (ORAU)

37. D. L. White

38. T. J. Wilbanks

39. ORNL patent Office

40. Central Research Office

41. Document Reference Section

42. Laboratory Records (RC)

43-45. Laboratory Records Dept.

\section{EXTERNAL DISTRIBUTION}

45. Dr. Douglas R. Bohi, Director, Energy and Natural Resources Division, Resources for the Future, 1616 P Street, N.W., Washington, DC 20036

46. Dr. Thomas E. Drabek, Professor, Department of Sociology, University of Denver, Denver, Colorado 80208-0209

47. Calvin MacCracken, President, Calmac Manufacturing Corporation, 101 West Sheffield Avenue, P. O. Box 710, Englewood, NJ 07631

48. Jacqueline B. Shragn, Director, Office of Technology Transfer, 405 Kirkland Hall, Vanderbilt University, Nashville, TN 37240

49. Mr. Georgc F. Sowers, P. E., Senior Vice President, Law Companies Group, Inc., 114 Townpark Drive, Suite 250, Kennesaw, Georgia 30144-5599

50. Dr. C. Michael Walton, Ernest H. Cockrell Centennial Chair in Engineering and Chairman, Department of Civil Engineering, University of Texas at Austin, Austin, Texas 78712-1076

51.-52. OSTI, U. S. Department of Energy, P. O. Box 62, Oak Ridge, Tennessee 37831

53. Office of Assistant Manager for Energy Research and Development, DOE/ORO, P. O. Box 2001 Oak Ridge, TN 37831-8600

54.-750. External Energy Efficiency and Renewables Section Distribution Mailing List and extra copies to E.M. Schorn, 4500N, H-19A 

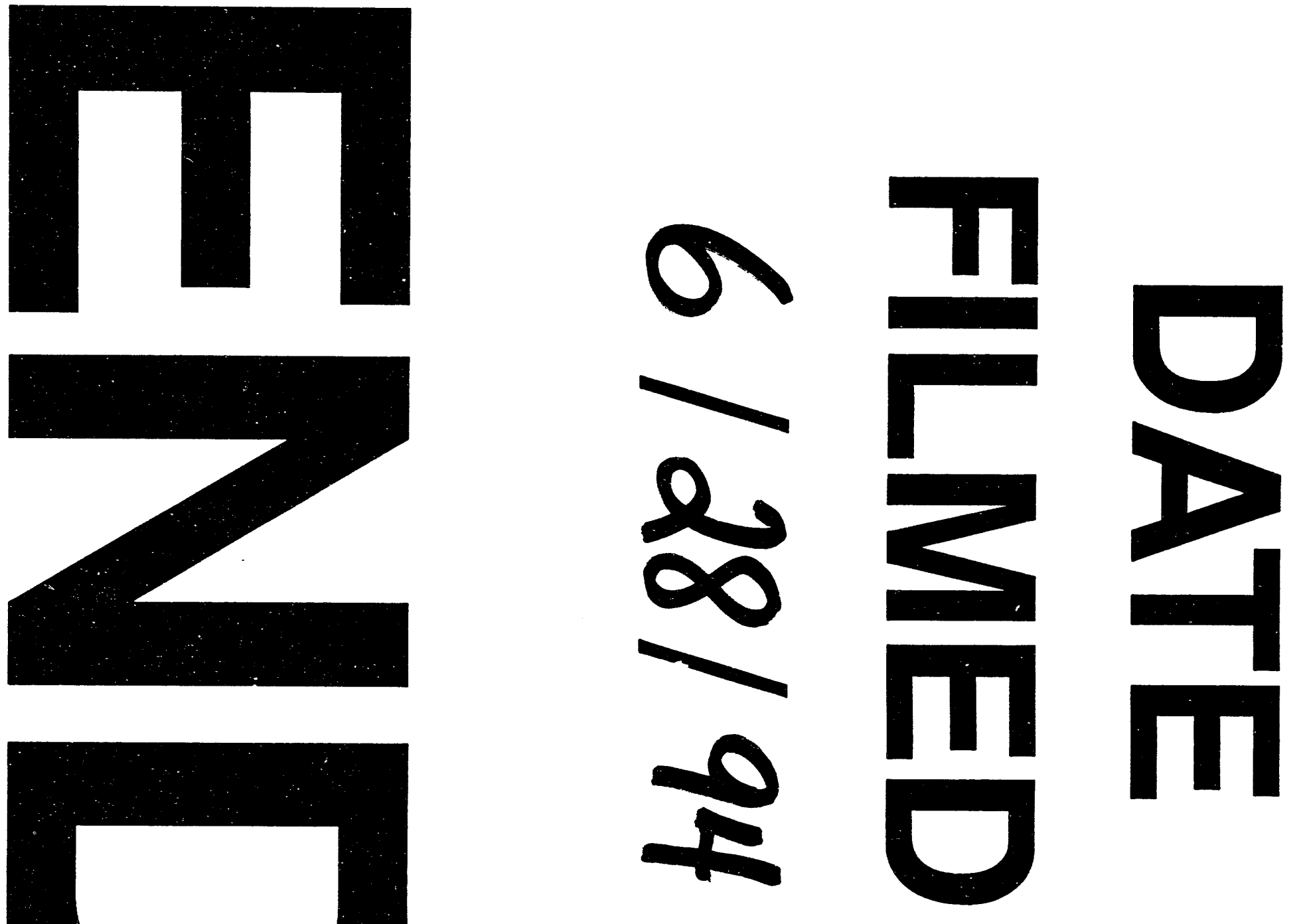
